Article

\title{
Structural Requirements for the Antifungal Activities of Natural Drimane Sesquiterpenes and Analogues, Supported by Conformational and Electronic Studies
}

\author{
Marcos Derita ${ }^{1}$, Iván Montenegro ${ }^{2}$, Francisco Garibotto ${ }^{3,4}$, Ricardo D. Enriz ${ }^{3,4}$, \\ Mauricio Cuellar Fritis ${ }^{2, \dagger}$ and Susana A. Zacchino ${ }^{1, \dagger, *}$ \\ 1 Farmacognosia, Facultad de Ciencias Bioquímicas y Farmacéuticas, \\ Universidad Nacional de Rosario, Suipacha 531, 2000 Rosario, Argentina \\ 2 Laboratorio de Ciencias Químicas y Recursos naturales, Facultad de Farmacia, \\ Universidad de Valparaíso, Avenida Gran Bretaña 1111, Playa Ancha, 2340000 Valparaíso, Chile \\ 3 Departamento de Química, Facultad de Química, Bioquímica y Farmacia, \\ Universidad Nacional de San Luis, Chacabuco 915, 5700 San Luis, Argentina \\ 4 IMIBIO-SL (CONICET), Chacabuco 915, 5700 San Luis, Argentina
}

$\dagger$ These authors contributed equally to this work.

* Author to whom correspondence should be addressed; E-Mail: szaabgil@citynet.net.ar; Tel.: +54-341-4375315.

Received: 18 December 2012; in revised form: 22 January 2013 / Accepted: 31 January 2013 / Published: 5 February 2013

\begin{abstract}
Seventeen drimanes including polygodial (1), isopolygodial (2), drimenol (3) and confertifolin (4) obtained from natural sources and the semi-synthetic derivatives 5-17 obtained from 1-3, were evaluated in vitro for antifungal properties against a unique panel of fungi with standardized procedures by using two end-points, $\mathrm{MIC}_{100}$ and $\mathrm{MIC}_{50}$. A SAR analysis of the whole series, supported by conformational and electronic studies, allowed us to show that the $\Delta^{7,8}$-double bond would be one of the key structural features related to the antifungal activity. The MEPs obtained for active compounds exhibit a clear negative minimum value (deep red zone) in the vicinity of the $\Delta^{7,8}$-double bond, which is not present in the inactive ones. Apart of this negative zone, a positive region (deep blue) appears in 1, which is not observed either in its epimer $\mathbf{2}$ nor in the rest of the active compounds. The $\log P$ of active compounds varies between 2.33 and 3.84, but differences in MICs are not correlated with concomitant variations in $\log P$ values.
\end{abstract}


Keywords: antifungal agents; drimanes; structure-activity relationships; stereo-electronic studies

\section{Introduction}

In the course of our ongoing search for antifungal compounds from natural sources, we recently reported that the aerial parts of Polygonum acuminatum Kunth., used in the Argentinean traditional medicine for ailments related to fungal infections [1], possessed antifungal properties against yeasts and dermatophytes, these results supporting their ethnopharmacological use [2]. Polygodial (1, Figure 1) was isolated from the most active extract as the main compound responsible for the activity, although other drimane derivatives such as isopolygodial (2) drimenol (3) and confertifolin (4) (Figure 1) showed antifungal properties too [2].

Figure 1. Drimanes isolated from Polygonum acuminatum.
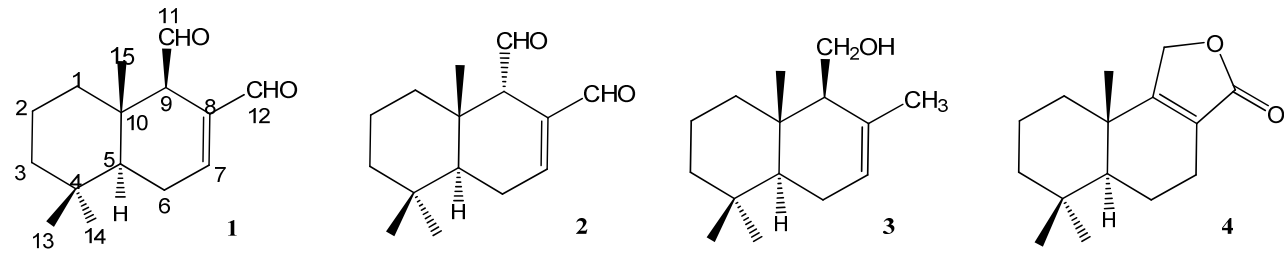

Although the claims that $\mathbf{1}$ possesses antifungal activity were consistent in all previous reports [3-6], contradictory reports were found in the literature regarding the antifungal activities of its natural analogue 2, which was variously reported to be either active or inactive, and based on this information, conflicting opinions about the main structural features required for drimanes to display antifungal activities were put forth. They can be summarized as follows: Fujita and Kubo stated that the $\beta$ - orientation of the C-9 carbonyl group was indispensable for activity, since $\mathbf{1}$ (with an aldehyde in the C-9 $\beta$ orientation) but not 2 (with a C-9 $\alpha$ aldehyde) possessed antifungal activity [7]. Conversely, Anke and Sterner [8] found that $\mathbf{2}$ did possess antifungal activity, although lower than that of $\mathbf{1}$, which was corroborated by us in the paper cited above [2] and in a subsequent one [9]. Another structural feature which was assigned a role in the antifungal activity was the $\alpha, \beta$-unsaturated $\mathrm{C}-8$ aldehyde moiety which, according to Taniguchi et al., was essential for activity [10]. However, this appears to be a contradiction with their own previous report in which 2 was devoid of antifungal activity, although it possess the $\alpha, \beta$-unsaturated C-8 aldehyde moiety [7,10]. Fujita and Kubo also reported that 1 lost its antifungal activity against Saccharomyces cerevisiae in certain media, because of formation of a pyrrole between its aldehydes and the amines present in the medium [7]. Considering that, with the formation of a pyrrole, both aldehydes disappear, this report opens a new question: if one or both aldehydes are necessary for the antifungal activity.

In order to clarify the main features required for drimanes to display antifungal activities, we tested herein a series of 17 compounds 1-17 (most of them not previously assayed for antifungal activities) for antifungal properties against a unique panel of nine fungal strains, with a standardized methodology, in the same laboratory. To guarantee confident and reproducible results, the whole series 
was tested following the Clinical and Laboratory Standards Institute (CLSI) [11,12] standardized procedures. CLSI has established consensus procedures to facilitate the agreement among laboratories in measuring the susceptibility of yeasts (updated in 2008 as M-27 A3) and of filamentous fungi (updated in 2008 as M-38 A2) to antifungal agents, with broth dilution methods. The standardized parameters detailed in both documents include protocols for the preparation of antifungal stock solutions, dilutions for testing, inocula, culture medium, temperature and incubation time, endpoint definitions and reference MIC ranges for microdilution testing of both, the established and newly introduced antifungal agents.

Among the tested analogues of $\mathbf{1}$, compounds 2-4 were isolated from $P$. acuminatum leaves and the remaining compounds 5-17 were prepared by isomerization, reduction, oxidation and methylenation reactions using the natural compounds 1, $\mathbf{2}$ and $\mathbf{3}$ as starting materials. They were tested against three yeasts: Candida albicans, S. cerevisiae and Cryptococcus neoformans; three Aspergillus spp. (A. flavus, A. fumigatus and A. niger) and three dermatophytes: Microsporum gypseum, Trichophyton rubrum and Trichophyton mentagrophytes by using two end-points $\mathrm{MIC}_{100}$ and $\mathrm{MIC}_{50}$. A SAR analysis of the whole series, supported by conformational and electronic studies on some selected compounds is presented herein, with the aim of determining the stereo-electronic characteristics related to the antifungal behavior and thus contribute to the understanding of the structural properties of antifungal drimanes.

\section{Results and Discussion}

\subsection{Chemistry}

Sesquiterpenes 1-4 were obtained from $P$. acuminatum leaves as described previously [2]. Compounds 1-3 were used as starting materials for the preparation of compounds 5-17.

\subsubsection{Compounds Obtained from 1}

Scheme 1 shows the modifications performed on compound $\mathbf{1}$ that led to compounds 5-8. Reduction of 1 with excess of $\mathrm{NaBH}_{4}$ in $\mathrm{MeOH}$ at $\mathrm{rt}$ produced (-)-(5S,10S)-(9R)-7-drimene-11,12-diol (5) and (-)-(5aS,9aS,9bR)-6,6,9a-trimethyl-1,3,5,5a,6,7,8,9,9a,9b-decahydronaphtho[1,2-c]furan (6). Isodrimeninol (7) was obtained by reduction of 1 with $0.5 \mathrm{mmol}_{\text {of }} \mathrm{NaBH}_{4}$ for each mmol of drimane and compound $\mathbf{8}$ was a methylenation product obtained by treating $\mathbf{1}$ with one equivalent of the bulky Tebbe's reagent, following previously reported procedures [13]. The identities of 5, 7 and $\mathbf{8}$ were established by comparison with previously reported data [13-16]. Compound 6, which was only previously reported once [16], is described in this work.

\subsubsection{Compounds Obtained from 2}

Scheme 2 shows the modifications performed on compound 2. Reduction of 2 with excess $\mathrm{NaBH}_{4}$ in $\mathrm{MeOH}$ at r.t. produced $(+)-(5 \mathrm{~S}, 10 S)-(9 S)-7-d r i m e n e-11,12$ diol (isodrimendiol, 9) [17] which, by catalytic hydrogenolysis using $\mathrm{Pd} / \mathrm{C}(10 \% \mathrm{Pd})$, was converted into isodrimenol $\mathbf{1 0}[15,18]$. Epoxidation of $\mathbf{9}$ with $m$-chloroperbenzoic acid (MCPBA) produced a single epoxide $\mathbf{1 1}$ in $75 \%$ yield. The 7-H signal in the ${ }^{1} \mathrm{H}-\mathrm{NMR}$ spectrum $(\delta 3.3$, brdd, $J=5.2 \mathrm{~Hz}, 5.2 \mathrm{~Hz})[19]$ and the signal for C-5, 
appearing at a $\delta 15.2 \mathrm{ppm}$ lower than that corresponding to 9 in the ${ }^{13} \mathrm{C}$-NMR spectrum, confirmed the $\alpha$ configuration of 11, as reported for similar compounds [20]. The epoxide 11 was refluxed with $\mathrm{LiAlH}_{4}$ in THF to afford the triol $\mathbf{1 2}$ in $85 \%$ yield. Oxidative degradation of $\mathbf{1 2}$ with sodium periodate gave the ketol 13 in $75 \%$ yield [21].

Scheme 1. Modifications performed on $\mathbf{1}$ to obtain compounds $\mathbf{5}-\mathbf{8}$.

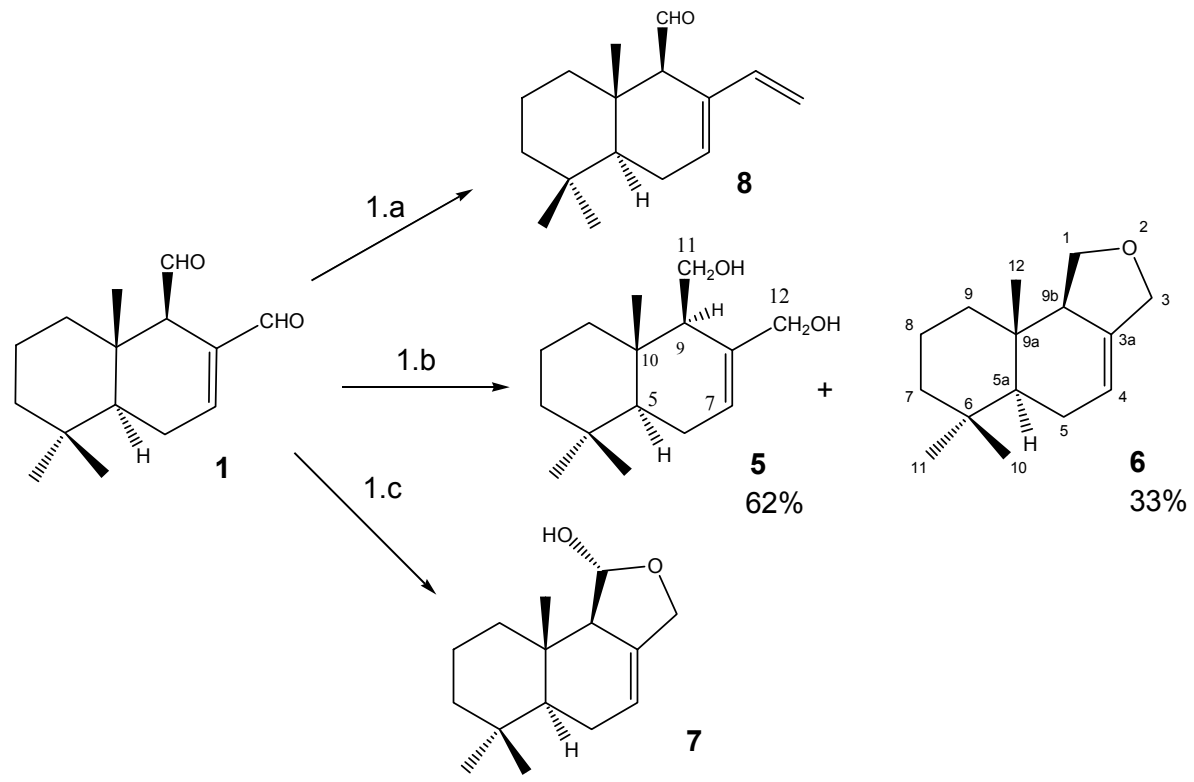

Conditions and reagents: (1.a) Tebbe's reagent $\left.\left(\mathrm{C}_{5} \mathrm{H}_{5}\right)_{2} \mathrm{TiCH}_{2} \mathrm{ClAl}_{(} \mathrm{CH}_{3}\right)_{2}$; (1.b) $\mathrm{NaBH}_{4}$ (excess), $\mathrm{MeOH}$ rt; (1.c) $\mathrm{NaBH}_{4}(0.5 \mathrm{mmol}$ per mmol of $\mathbf{1}), \mathrm{MeOH}$ rt.

Scheme 2. Modifications performed on 2 to obtain compounds 9-13.

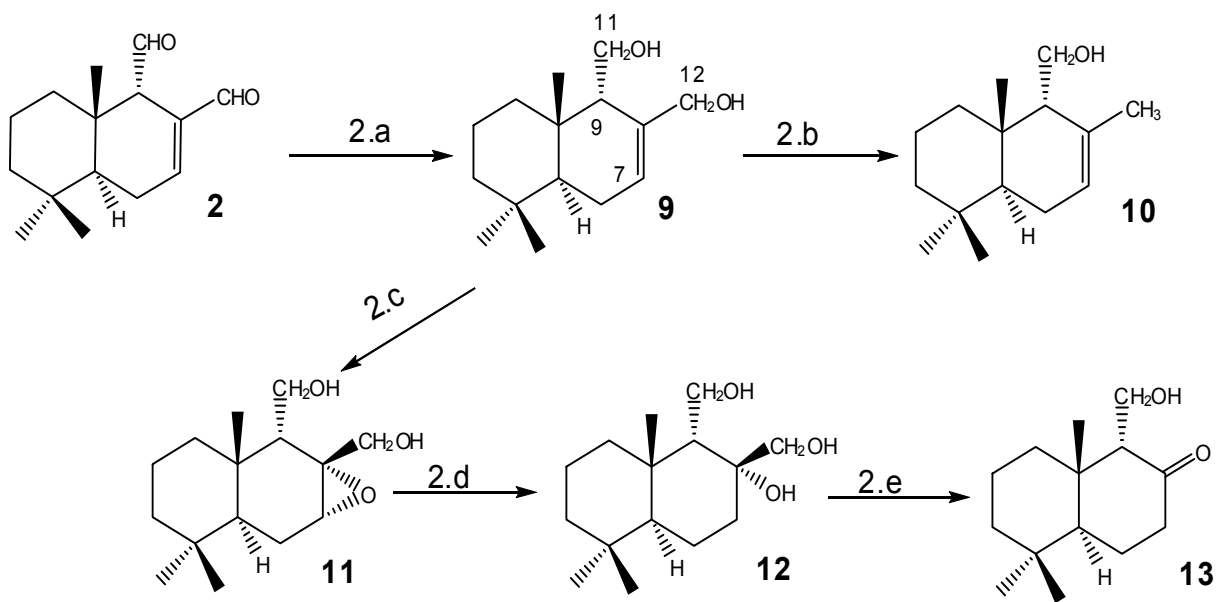

Conditions and reagents: (2.a) $\mathrm{NaBH}_{4}$ (excess), $\mathrm{MeOH}$ rt; (2.b) $\mathrm{H}_{2}, \mathrm{Pd} / \mathrm{C}(10 \%)$; (2.c) MCPBA, DCM; (2.d) $\mathrm{LiAlH}_{4}$, THF; (2.e) $\mathrm{NaIO}_{4}, \mathrm{THF} / \mathrm{H}_{2} \mathrm{O}$.

\subsubsection{Compounds Obtained from 3}

Scheme 3 shows the modifications performed on $\mathbf{3}$. Oxidation of $\mathbf{3}$ with Jones reagent afforded drimenal 14 and the unsaturated ketone 15. On the other hand, the unsaturated ketone 16 was obtained by treating 3 with the oxidation reagent pyridinium chlorochromate (PCC) [14]. Their structures were determined by comparison with the previously reported data [14,22,23]. In addition, catalytic 
hydrogenation of 3 using $\mathrm{Pd} / \mathrm{C}(10 \% \mathrm{Pd})$, led to the saturated drimanol 17 whose spectroscopic data were in accordance to the literature [24].

Scheme 3. Modifications performed on 3 to obtain compounds 14-17.

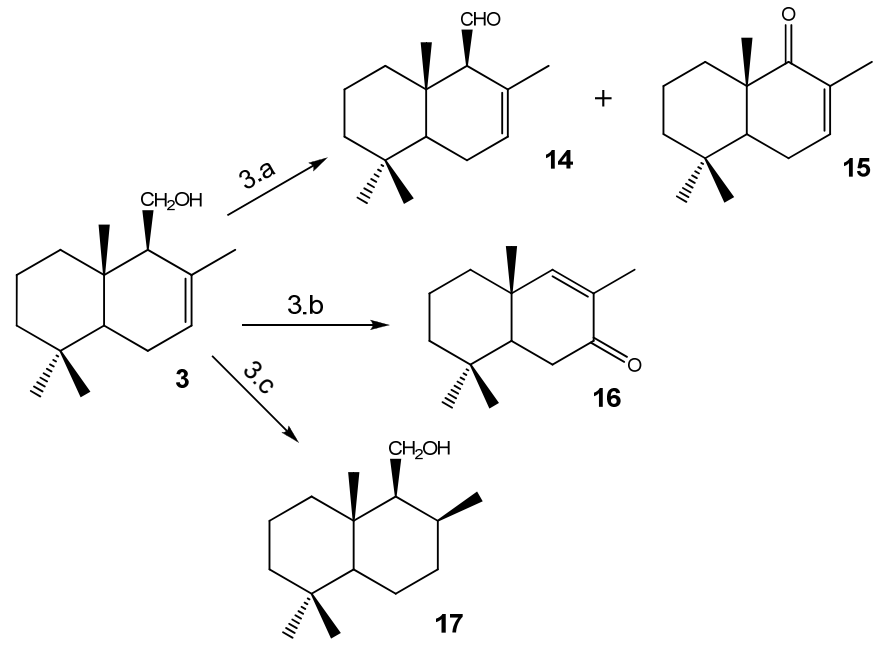

Conditions and reagents: (3.a): Jones reagent; (3.b): Pyridinium chlorochromate (PCC); (3.c) $\mathrm{H}_{2}$, $\mathrm{Pd} / \mathrm{C}(10 \%)$.

\subsection{Antifungal Activity}

To carry out the antifungal evaluation, concentrations of naturally occurring drimanes $\mathbf{1}-\mathbf{4}$ and semi-synthetic derivatives 5-17 up to $250 \mu \mathrm{g} / \mathrm{mL}$ were incorporated to growth media according to CLSI guidelines [11]. Table 1 summarizes the concentration of drimanes that completely inhibited $\left(\mathrm{MIC}_{100}\right)$ the growth of nine opportunistic pathogenic fungi including yeasts $(C$. albicans, C. neoformans, and S. cerevisiae), hialohyphomycetes (Aspergillus spp.) as well as dermatophytes (Microsporum and Trichophyton spp). In addition to MIC determinations, the Minimum Fungicidal Concentration (MFC) of each active compound against this panel was accomplished by sub-culturing a sample of media from MIC tubes showing no growth, onto drug free agar plates (Table 1).

Table 1. Minimum Inhibitory Concentration $\left(\mathrm{MIC}_{100}\right)$ and Minimum Fungicidal Concentration (MFC) of naturally occurring (1-4) and semi-synthetic (5-17) drimanes, against human opportunistic pathogenic fungi.

\begin{tabular}{|c|c|c|c|c|c|c|c|c|c|c|c|}
\hline \multicolumn{2}{|c|}{ Compounds } & & \multicolumn{3}{|c|}{ Yeasts } & \multicolumn{3}{|c|}{ Aspergillus spp } & \multicolumn{3}{|c|}{ Dermatophytes } \\
\hline $\mathrm{N}^{\circ}$ & Structure & & $\mathrm{Ca}$ & $S c$ & $C n$ & Afum & $A f l$ & $A n$ & $M g$ & $T r$ & $T m$ \\
\hline \multirow{2}{*}{1} & & $\mathrm{MIC}_{100}$ & 3.9 & 15.6 & 7.8 & I & I & $\mathrm{I}$ & 62.5 & 62.5 & 62.5 \\
\hline & & MFC & 7.8 & 31.2 & 7.8 & - & - & - & 125 & 125 & 125 \\
\hline \multirow[t]{2}{*}{2} & & $\mathrm{MIC}_{100}$ & 62.5 & 62.5 & 62.5 & I & I & I & 62.5 & 62.5 & 62.5 \\
\hline & & MFC & 125 & 125 & 125 & - & - & - & 125 & 125 & 125 \\
\hline \multirow[t]{2}{*}{3} & & $\mathrm{MIC}_{100}$ & I & I & 125 & I & I & I & 62.5 & 62.5 & 62.5 \\
\hline & & MFC & - & - & I & - & - & - & 125 & 125 & 125 \\
\hline
\end{tabular}


Table 1. Cont.

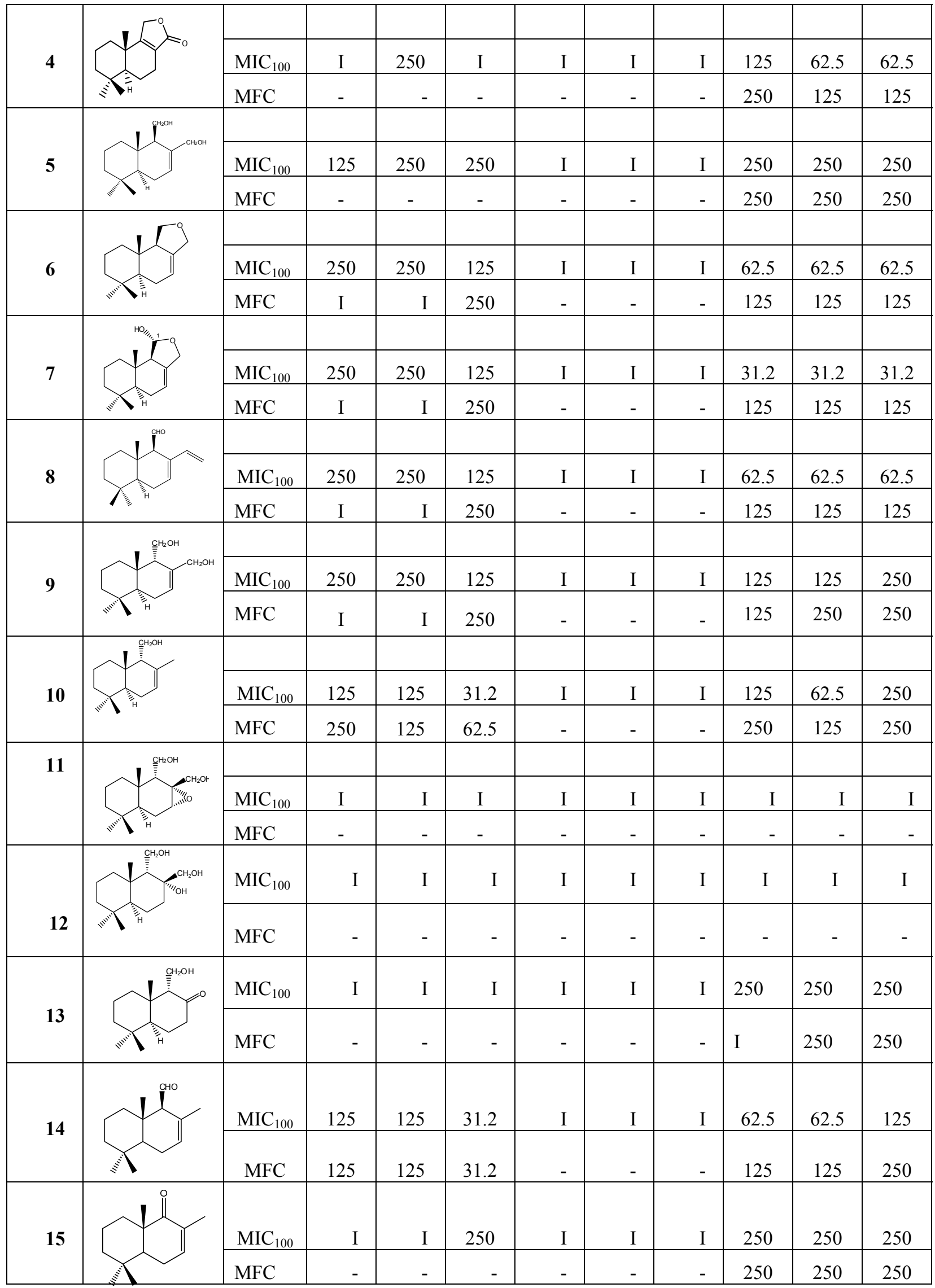


Table 1. Cont.

\begin{tabular}{|c|c|c|c|c|c|c|c|c|c|c|c|}
\hline \multirow{2}{*}{16} & & $\mathrm{MIC}_{100}$ & 250 & 250 & 250 & I & I & I & 250 & 250 & 250 \\
\hline & & MFC & I & I & 250 & - & - & - & 250 & 250 & 250 \\
\hline \multirow[t]{2}{*}{17} & & $\mathrm{MIC}_{100}$ & I & I & I & I & I & I & I & I & I \\
\hline & 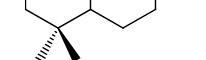 & MFC & - & - & - & - & - & - & - & - & - \\
\hline & \multirow{4}{*}{$\begin{array}{l}\text { St drugs } \\
\text { Amph B } \\
\text { Terbinafine } \\
\text { Ketoconazole }\end{array}$} & & & & & & & & & & \\
\hline & & MIC & 0.78 & 0.50 & 0.25 & 0.50 & 0.50 & 0.50 & 0.12 & 0.075 & 0.075 \\
\hline & & MIC & 1.56 & 3.12 & 0.39 & 0.78 & 0.78 & 1.56 & 0.04 & 0.01 & 0.025 \\
\hline & & MIC & 0.5 & 0.5 & 0.25 & 0.12 & 0.5 & 0.25 & 0.05 & 0.025 & 0.025 \\
\hline
\end{tabular}

Ca: Candida albicans ATCC 10231, Sc: Saccharomyces cerevisiae ATCC 9763, Cn: Cryptococcus MIC $_{50}(\mu \mathrm{g} / \mathrm{mL})$ neoformans ATCC 32264; An: Aspergillus niger ATCC 9029, Afu: Aspergillus fumigatus ATCC 26934; Afl: Aspergillus flavus ATCC 9170, Mg: Microsporum gypseum C 115; Tr: Trichophyton rubrum C113, Tm: Trichophyton mentagrophytes ATCC 9972; Amph B: Amphotericin B. I: inactive $(\mathrm{MIC}>250 \mu \mathrm{g} / \mathrm{mL})$.

Regarding the sensitivity of the different fungi to drimanes, it can be stated that: (i) all compounds, but not 11, 12 and 17, exhibited moderate activity (MICs $\leq 250 \mu \mathrm{g} / \mathrm{mL}$ ) against dermatophytes and yeasts; (ii) no member of the series was active against Aspergillus spp; (iii) all active compounds showed fungicidal rather than fungistatic properties against most fungi, since they not only inhibit but also kill them at Minimum Fungicidal Concentrations (MFC) $\leq 250 \mu \mathrm{g} / \mathrm{mL}$.

\subsection{Structure-Activity Relationships (SAR)}

Since no differences in MICs among the members were observed against dermatophytes (one-dilution-step MIC changes are within the range of experimental error) [25], the SAR studies were performed on the activity of the series against yeasts (C. albicans, S. cerevisiae and C. neoformans) which showed striking differences.

For a better analysis of the differential behavior of these compounds against yeasts, we selected the clinically important fungi $C$. neoformans and $C$. albicans as targets. $C$. neoformans is a fungus that remains an important life-threatening complication for immunocompromised hosts, particularly for patients who have undergone transplantation of solid organs [26]. Therefore, the activity of compounds against this fungus has a true clinical relevance. In turn, $C$. albicans is one of the leading causes of nosocomial blood stream infections worldwide [27].

Thus, compounds 1-10, 14-16 that showed activity against at least one yeast were re-tested against the standardized strains C. albicans ATCC 10231 and C. neoformans ATCC 32264 determining, this time, $\mathrm{MIC}_{50}$ (the minimum concentration of compounds that inhibit $50 \%$ of growth), a less stringent end-point highly used [27] and recommended by CLSI [10]. $\mathrm{MIC}_{50}$ consistently represent the in vitro activity of compounds and many times provide a better correlation with other measurements of antifungal activity [27]. Results are shown in Table 2. 
Table 2. $\mathrm{MIC}_{50}$ values of representative members of the drimane series against $C$. albicans ATCC 10231 (Ca) and C. neoformans ATCC $32264(C n)$.

\begin{tabular}{cccc}
\hline \multicolumn{4}{c}{ MIC $_{\mathbf{5 0}}(\boldsymbol{\mu \mathbf { g }} / \mathbf{m L})$} \\
\hline & $C a$ & $C n$ & $\log P$ \\
1 & 1.9 & 1.9 & 2.33 \\
2 & 31.2 & 31.2 & 2.33 \\
3 & 62.5 & 31.2 & 3.83 \\
4 & 62.5 & 62.5 & 3.35 \\
5 & 250 & 250 & 2.76 \\
6 & 62.5 & 31.2 & 3.40 \\
7 & 62.5 & 31.2 & 3.24 \\
8 & 31.2 & 31.2 & 3.67 \\
9 & 250 & 31.2 & 2.77 \\
10 & 62.5 & 15.6 & 3.83 \\
14 & 62.5 & 62.5 & 3.53 \\
15 & 250 & $\mathrm{I}$ & 3.84 \\
16 & 31.2 & 62.5 & 3.37 \\
17 & $\mathrm{I}$ & $\mathrm{I}$ & 4.30 \\
Amphotericin B & 0.78 & 0.25 & \\
\hline
\end{tabular}

From the analysis of the structures and the activities displayed by all compounds against C. albicans and $C$. neoformans, some structure-activity relationships can be extracted. They were grouped according to the influence of each structural feature such as $\Delta^{7,8}$-double bond in the drimane skeleton, configuration of C-9, presence of an aldehyde at C-9 (or at C-8) and presence of an $\alpha, \beta$-unsaturated aldehyde moiety at C-8.

2.3.1. Role of the $\Delta^{7,8}$-Double Bond in the Drimane Skeleton Alone and in $\alpha, \beta$ Position Respective to the Aldehyde on $\mathrm{C}-8$

The $\Delta^{7,8}$-double bond in the drimane scheleton appears to be one of the necessary structural features for antifungal activity since inactive compounds 11, 12, 13 and 17 all lack this $\Delta^{7,8}$-double bond. The comparison of the activities of $\mathbf{3}$ with its saturated derivative $\mathbf{1 7}$ (devoid of antifungal activity), clearly reinforces this observation. A computer-assisted analysis supporting this observation is presented below, in Section 2.4.

In addition, it can be observed that the $\Delta^{7,8}$-double bond in active structures can be found either alone as in compounds 3, 5-10 and 14, or as being part of the C-8 $\alpha, \beta$-unsaturated aldehyde moiety (constituting a Michael acceptor group) as in compounds $\mathbf{1}$ and 2. The fact that both drimane structural types do display antifungal activity suggests that antifungal drimanes could not act via a Michael addition. This finding differs from the antifungal structural requirements of some other sesquiterpenes such as the sesquiterpenelactones (+)-costunolide and (-)-dehydrocostunolide isolated from Centaurea plants [28] and the synthetic tuberiferin and dehydrobrachylaenolide [29], whose antifungal activities were reported to be enhanced by a Michael acceptor group. Nevertheless, our findings are not in any way strange since many other diverse structural compounds not containing a Michael acceptor group, were found to display strong antifungal properties [30,31]. 


\subsubsection{Role of the Configuration of C-9}

The comparison of activities of $\mathbf{1}$ and $\mathbf{2}$ shows that, in contrast to Fujita and Kubo's previous report [7], both compounds do possess antifungal activity. However, the $9 \alpha$-derivative 2 displays 16 and eight times lower activity than its epimer 1, against C. albicans and C. neoformans, respectively. This result is consistent with Anke and Sterner's [8] and Derita et al.'s [2] previous studies, who both found that $\mathbf{2}$ did display antifungal activities, but lower than $\mathbf{1}$. The different antifungal activities displayed by compounds $\mathbf{1}$ and $\mathbf{2}$ are supported by their different electronic distributions which are presented in Section 2.4.

\subsubsection{Role of an Aldehyde at C-9 and of $\mathrm{a} \mathrm{CH}_{2} \mathrm{OH}$ at C-8}

The presence of an aldehyde group at C-9 appears not to be indispensable for activity, as can be observed in compounds 3-7, 9, 10, 15 and 16. Otherwise, the comparison of diol 9 with the monoalcohol 10, suggests that a $\mathrm{CH}_{2} \mathrm{OH}$ at $\mathrm{C}-8$ does not contribute to the activity either.

\subsection{Conformational and Electronic Studies}

To gain a better understanding of the above experimental results, computer-assisted conformational and electronic studies were performed on all compounds of the series. The purpose was to obtain precise information about the antifungal drimanes' stereoelectronic characteristics that give support to the relationships between structure and activity.

\subsubsection{Conformational Analysis}

For the conformational analysis, each ring of the drimane scheleton was named A and B (Figure 2). The essential conformational problem of drimane sesquiterpenes, involves two aspects:

(a) The conformational behavior of torsional angles $\phi_{1}-\phi_{5}$ which determines the spatial ordering of ring A.

(b) The orientation of torsional angles $\phi_{6}-\phi_{9}$ which determines the overall shape of ring $\mathrm{B}$. In this ring, they are also important torsional angles $\phi_{10}$ and $\phi_{11}$, which are related to $\mathrm{CH}_{2} \mathrm{OH}$ substituents as $\mathrm{R}_{2}$ or $\mathrm{R}_{1}$.

Our B3LYP/6311G(d.p) calculations indicated that a chair, and not a boat form, is the energetically preferred spatial ordering for ring $\mathrm{A}$ in compound 1. The energy gap obtained between both conformers is $14.7 \mathrm{Kcal} / \mathrm{mol}$, indicating that this compound is fairly rigid and possesses a restricted conformational flexibility. Similar results were obtained for all compounds possessing this structural feature like compounds $\mathbf{1}-\mathbf{3}, \mathbf{5}, \mathbf{8}-\mathbf{1 0}$ and 14. Considering that, in these compounds, ring $\mathrm{B}$ is a cyclohexene, each of the three possible conformations: sofa (also called half-boat), half-chair and boat, were evaluated. 
Figure 2. General representation of drimanes reported here, showing the torsional angles that determine the spatial ordering of rings A and B.

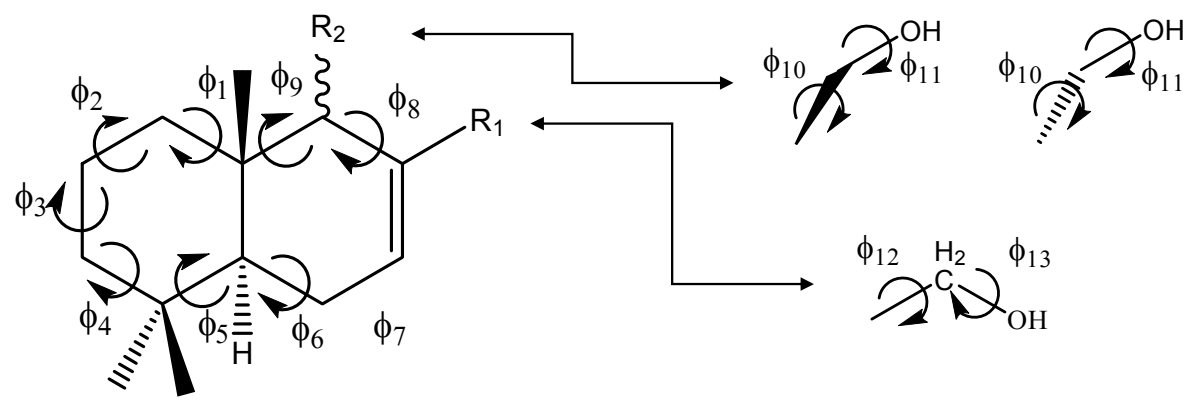

Our theoretical results indicated that the so-called "half-boat" conformation is the highly preferred low-energy form Figure 3 a which is in agreement with experimental data obtained for structurally related compounds [32-34]. Considering that all these compounds adopt similar low flexible conformations, it is clear that this would not be the cause of the different activities displayed against fungi. The same can be said for compounds 4, 6 and 7, for which our theoretical calculations indicate that the conformational flexibility is even more restricted than the observed for the above compounds as a consequence of the presence of a third fused ring. The energetically preferred conformation obtained for compound $\mathbf{6}$ is shown in Figure 3b. Closely similar conformations were obtained for compounds 4 and 7.

Figure 3. Spatial view of the lowest energy conformations obtained for compounds 1 (a) and 6 (b) from DFT (B3LYP/6-311G(d,p) optimizations. The chair and half-boat forms adopted by rings $\mathrm{A}$ and $\mathrm{B}$ respectively, may be appreciated in this figure.

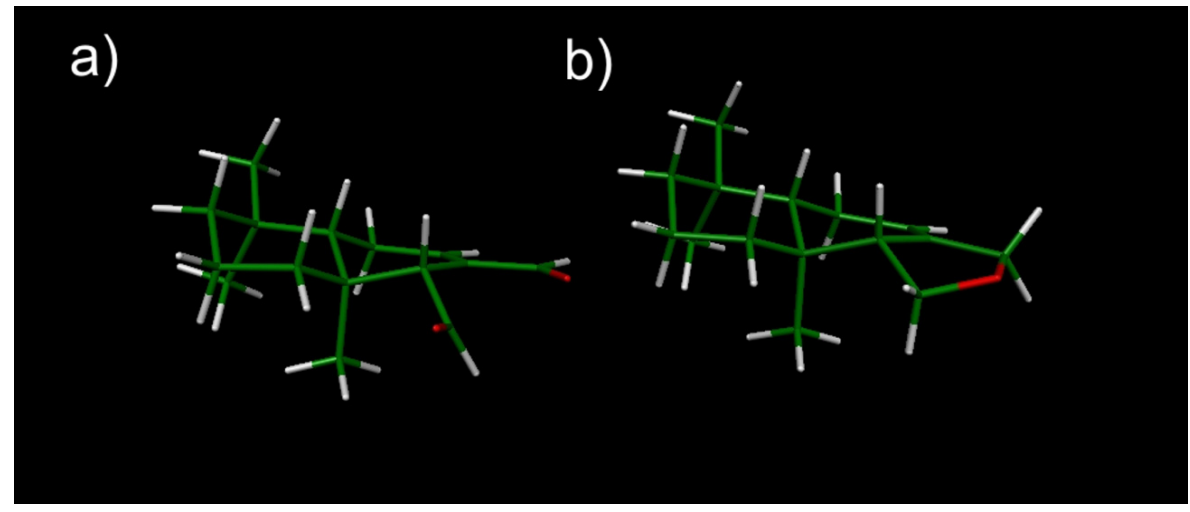

Thus, the knowledge of the stereo-electronic properties of these drimanes will surely help to elucidate the structural requirements for the antifungal activity. For this analysis, Molecular Electrostatic Potentials (MEPs) are particularly valuable, because they allow the visualization and assessment of the capacity of a molecule to interact electrostatically with a putative-binding site [35-37].

Figure 4 gives the MEPs obtained for compounds 1, 2 and 5, which showed high, moderate and low activities respectively. The MEP obtained for $\mathbf{1}$ (Figure 4a) exhibits three characteristic regions: a clear negative minimum value (deep red zone with $\mathrm{V}(\mathrm{r})_{\min } \approx-0.1139 \mathrm{el} / \mathrm{au}^{3}$ ) in the vicinity of $\Delta^{7,8}$ double bond; a positive region (deep blue zone with $\mathrm{V}(\mathrm{r})_{\max } \approx 0.1136 \mathrm{el} / \mathrm{au}^{3}$ ) located near the $\mathrm{CH}_{3}$ group at $\mathrm{C}_{10}$; and an extended hydrophobic zone (deep and light green zone with an almost neutral potential 
$\left.\mathrm{V}(\mathrm{r})_{\text {med }} \approx-0.0011 \mathrm{el} / \mathrm{au}^{3}\right)$ in the rest of the molecule. Considering that $\mathbf{1}$ is the most active of the series, this MEP should account for the characteristics of the electronic general pattern for all the molecules possessing antifungal effect. Interestingly, the MEP obtained for its epimer 2 (Figure 4b), showed a marked electronegative zone near the double bond $\Delta^{7,8}$ similar to the showed by $\mathbf{1}$ but a little smaller. In turn, the positive zone is not observed in $\mathbf{2}$ which is a clear difference with $\mathbf{1}$. Regarding compound $\mathbf{5}$, concomitantly with its lower activity, it showed a red negative zone but considerably smaller than that of 2 (Figure 4c).

Figure 4. Electrostatic potential-encoded electron density surfaces of compounds 1 (a), 2 (b) and 5 (c). The surfaces were generated using B3LYP/6-311G++(d,p) single point calculations. The coloring represents electrostatic potential with red and blue indicating the electronegative or the electropositive areas respectively. The color-coded is shown at the left, where red is representing the most negative and the blue, the most positive values, respectively. Intermediate negative and positive values are represented by colours that downgrades from orange to light blue.

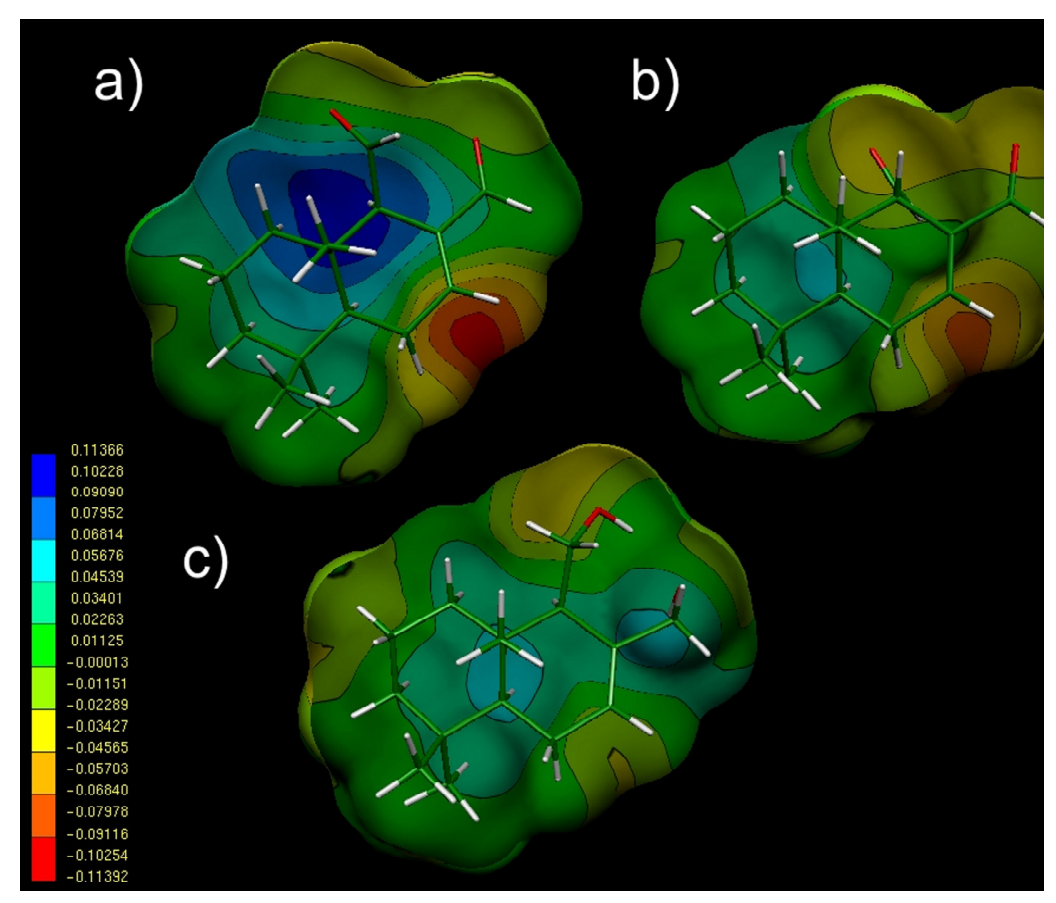

For the inactive compounds $\mathbf{1 3}$ and $\mathbf{1 7}$, the electronegative zone is totally missing (Figure 5). This is an expected result considering that these compounds do not possess a double bond in such portion of their structures.

Finally, we calculated $\log P$ (the logarithm of the partition coefficient in a biphasic system, e.g., n-octanol/water) for all drimanes which are shown in Table 2. It is known that $\log P$ describes the macroscopic hydrophobicity of a molecule, which is a factor related to its ability to penetrate membranes of fungal cells and to reach the interacting sites, thus influencing the antifungal activity of compounds [38]. $\log P$ values for the different active drimanes of the series varied from 2.33 to 3.84 , which fall within the range of values observed for other antifungal compounds [31,39,40]. However, although these values indicate that they all are lipophilic compounds $[39,41], \log P$ have similar values for drimanes with clear different activity, suggesting that this parameter would not have a direct 
correlation with the antifungal activity of the compounds of Table 2 when acting against $C$. albicans and C. neoformans.

Figure 5. Molecular Electrostatic Potential (MEPs) obtained for compounds 13 (a) and 17 (b).

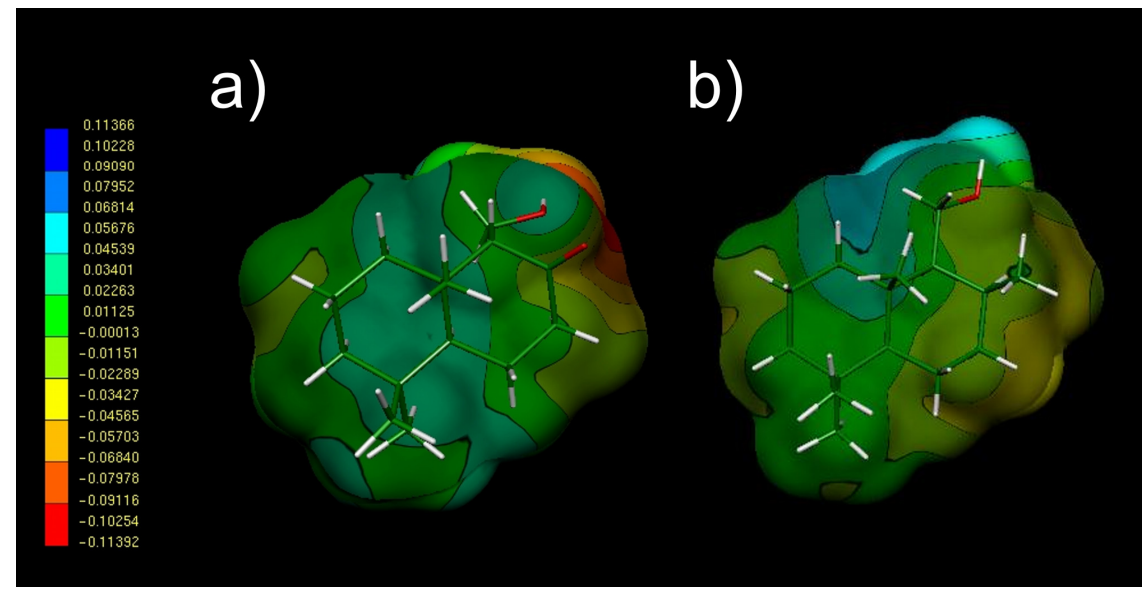

Thus, the most active drimane 1 and its epimer 2 , both possess the same $\log P$ value $=2.33$ yet their activity is quite different. The same can be observed for compound $\mathbf{1 4}$ which has a $\log P=3.53$ and displays lower activities. This behavior of drimanes was dissimilar to that of sesquiterpene lactones, for which a clear inverse relationship between polarity and antifungal activity was observed [28,29]. However, we must take into account that the sesquiterpene lactone skeletons are quite different from those of the drimane sesquiterpenes. In addition, different fungal species were used as the test species in each work; here, the yeasts $C$. albicans and $C$. neoformans were used, while in the previous reports the filamentous fungus Cunninghamella echinulata [28] and Phycomyces blakesleeanus were used [29]. It has been often observed completely different behaviors for certain compounds towards different type of fungi [42]. As the authors stated in [28], there is not much information about the chemical structureantifungal activity relationships for sesquiterpenoids and deeper studies should be necessary. In this work, we add information that could be useful for a better knowledge of drimane sesquiterpenes behavior against human opportunistic and pathogenic fungi.

\section{Experimental}

\subsection{Chemistry}

Melting points were determined in a Büchi melting point apparatus and are uncorrected. The ${ }^{1} \mathrm{H}-$ and ${ }^{13} \mathrm{C}$-NMR spectra were run on a Bruker DPX 300 spectrometer operating at 300 and $75 \mathrm{MHz}$, respectively, using chloroform- $d$ as solvent and tetramethylsilane as internal standard. The mass spectra were scanned on a Hewlett Packard HP Engine-5989 spectrometer (equipped with a direct inlet probe) operating at $70 \mathrm{eV}$.

\subsubsection{Isolation of Natural Compounds $\mathbf{1}-\mathbf{4}$}

Compounds 1-4 were isolated from DCM extracts of leaves of $P$. acuminatum Kunth. (Polygonaceae) collected on the bank of Coronda River at Puerto Gaboto, Santa Fe Province, 
Argentina, in March 2010. The plant was identified by Prof. Susana Gattuso and a voucher specimen was deposited at the Herbarium of the Vegetal Biology Area of UNR, Suipacha 531, Rosario, Argentina (UNR \# 2359). The extraction methodology and isolation of pure compounds was performed according to reported procedures [1]. Compounds 1-4 were identified by micromelting point, optical rotation and spectroscopic data, including ${ }^{1} \mathrm{H}-$ and ${ }^{13} \mathrm{C}-\mathrm{NMR}$ [43-47] and were compared with authentic samples obtained previously in our laboratory [1,48,49] for polygodial (1) and isopolygodial (2) or with literature data [50,51], for drimenol (3) and for confertifolin $(4)[44,52]$.

\subsubsection{General Procedure for Synthesis of $\mathbf{5}$ and $\mathbf{6}$}

To a magnetically well-stirred solution of $\mathbf{1}(2.1 \mathrm{mmol})$ in $\mathrm{MeOH}(25 \mathrm{~mL})$ acidified with 5 drops of $1 \mathrm{M} \mathrm{HCl}, \mathrm{NaBH}_{4}(8.4 \mathrm{mmol})$ was added carefully in small portions. The mixture was refluxed at $50{ }^{\circ} \mathrm{C}$ for $4 \mathrm{~h}$ and most of the solvent was evaporated in vacuo. Water $(20 \mathrm{~mL})$ was added cautiously and extractions with EtOAc were performed. The organic phase was dried with $\mathrm{MgSO}_{4}$, evaporated and submitted to column chromatography $(\mathrm{CC})$ to give compounds $5(1.3 \mathrm{mmol})$ and $\mathbf{6}(0.7 \mathrm{mmol})$ in yields of $62 \%$ and $33 \%$, respectively.

(-)-(5S,10S)-(9R)-7-Drimene-11,12diol (drimendiol) (5): White solid; mp: $74{ }^{\circ} \mathrm{C} ;[\alpha]_{\mathrm{D}}{ }^{25}-8^{\circ}\left(\mathrm{CHCl}_{3}, c\right.$ = 1.0). IR (film) $v_{\max } 3286,2924 \mathrm{~cm}^{-1} .{ }^{1} \mathrm{H}-\mathrm{NMR}: \delta 5.78(1 \mathrm{H}, m, \mathrm{H}-7) ; 4.33(1 \mathrm{H}, d, J=11.9 \mathrm{~Hz}$, $\mathrm{H}-12 \mathrm{~B})$; $4.00-3.90(4 \mathrm{H}, m, \mathrm{H}-11 \mathrm{~B}, 12 \mathrm{~A}$ and $2 \mathrm{OH}) ; 3.64(1 \mathrm{H}, d d, J=8.7$ and $10.4 \mathrm{~Hz}, \mathrm{H}-11 \mathrm{~A})$; 2.15-1.90 (4H, $m, \mathrm{H}-1 \beta, 6 \alpha, 6 \beta$ and 9$) ; 1.58-1.40$ (3H, $m, \mathrm{H}-2 \alpha, 2 \beta$ and $3 \beta) ; 1.24-1.10$ (3H, $m, \mathrm{H}-1 \alpha$, $3 \alpha$ and 5); 0.88 and $0.86\left(6 \mathrm{H}, 2 s, 13-\mathrm{Me}\right.$ and 14-Me); 0.75 (3H, s, 15-Me). ${ }^{13} \mathrm{C}-\mathrm{NMR}: \delta 136.9(\mathrm{C}-8)$; 127.1 (C-7); 67.3 (C-12); 61.2 (C-11); 54.4 (C-5); 49.4 (C-9); 42.0 (C-3); 39.3 (C-1); 35.6 (C-10); 33.2 (C-13); 32.9 (C-4); 23.5 (C-6); 21.9 (C-14); 18.8 (C-2); 14.5 (C-15). MS m/z (EI): 238 [M ${ }^{+}$. All these data are coincident with the literature $[13,16]$.

(-)-(5aS,9aS,9bR)-6,6,9a-Trimethyl-1,3,5,5a,6,7,8,9,9a,9b-decahydronaphtho[1,2-c]furan $\quad(6): \quad[\alpha]_{\mathrm{D}}{ }^{25}$ $-17^{\circ}\left(\mathrm{CHCl}_{3}, c=1.0\right)$, IR (film) $v_{\max } 2980,1660,1460,1380,1365 \mathrm{~cm}^{-1} .{ }^{1} \mathrm{H}-\mathrm{NMR}: \delta 5.80(1 \mathrm{H}, m$, $\mathrm{H}-4) ; 4.35(1 \mathrm{H}, d d, J=1.1$ and $12.0 \mathrm{~Hz}, \mathrm{H}-3 \beta) ; 3.99(1 \mathrm{H}, d, J=12.0 \mathrm{~Hz}, \mathrm{H}-3 \alpha) ; 3.91(1 \mathrm{H}, d d, J=2.1$ and $10.9 \mathrm{~Hz}, \mathrm{H}-1 \alpha) ; 3.68(1 \mathrm{H}, d d, J=8.3,10.9 \mathrm{~Hz}, \mathrm{H}-1 \beta) ; 2.15(1 \mathrm{H}, m, \mathrm{H}-9 \mathrm{~b}) ; 2.20-1.20(9 \mathrm{H}, m$, $\mathrm{H}-9 \alpha$ and $\beta, \mathrm{H}-8 \alpha$ and $\beta, \mathrm{H}-7 \alpha$ and $\beta, \mathrm{H}-5 \alpha$ and $\beta, \mathrm{H}-5 \mathrm{a}) ; 0.90$ and 0.88 (6H, $2 s, 12-\mathrm{Me}$ and 11$)$; 0.77 (3H, s, 10-Me). ${ }^{13} \mathrm{C}-\mathrm{NMR}: \delta 136.9$ (C-3a), 127.4 (C-4); 67.4 (C-3); 61.4 (C-1); 54.4 (C-9b); 49.4 (C-5a); 42.0 (C-7); 39.3 (C-9); 35.6 (C-9a); 33.2 (C-11); 32.9 (C-6); 23.6 (C-5); 21.9 (C-10); 18.8 (C-8); $14.5(\mathrm{C}-12)$. MS $m / z(\mathrm{EI}): 220\left[\mathrm{M}^{+}\right]$. This is the first time that this compound is described in detail.

\subsubsection{Synthesis of (-)-(1R,5aS,9aS,9bR)-6,6,9a-Trimethyl-1,3,5,5a,6,7,8,9,9a,9b-decahydro} naphto[2,1c]furan-1-ol (isodrimeninol, 7)

Compound $1(0.55 \mathrm{mmol})$ was dissolved in $\mathrm{MeOH}(10 \mathrm{~mL})$ acidified with 3 drops of $1 \mathrm{M} \mathrm{HCl}$ and $\mathrm{NaBH}_{4}(0.27 \mathrm{mmol})$ was added carefully in small portions. The mixture was stirred during $30 \mathrm{~min}$ at $0{ }^{\circ} \mathrm{C}$ and then for $3 \mathrm{~h}$ at $\mathrm{rt}$. Water $(10 \mathrm{~mL})$ was added cautiously and extractions with EtOAc were performed. The organic phase was dried with $\mathrm{MgSO}_{4}$, evaporated and submitted to $\mathrm{CC}$ to give compound $7(0.39 \mathrm{mmol})$ in $71 \%$ yield. Colorless oil; $[\alpha]_{\mathrm{D}}{ }^{25}-12^{\circ}\left(\mathrm{CHCl}_{3}, c=1.0\right)$; IR (film) $v_{\max }$ 
3400, 1630, 1390, 1370, $\mathrm{cm}^{-1} .{ }^{1} \mathrm{H}-\mathrm{NMR}: \delta 5.52(1 \mathrm{H}, m, \mathrm{H}-4) ; 5.29(1 \mathrm{H}, \mathrm{br} d, J=2.2 \mathrm{~Hz}, \mathrm{H}-1) ; 4.50$ $(1 \mathrm{H}, \mathrm{br} d, J=11.3 \mathrm{~Hz}, \mathrm{H}-3 \beta) ; 4.19(1 \mathrm{H}, \mathrm{br} d, J=11.3 \mathrm{~Hz}, \mathrm{H}-3 \alpha) ; 3.04(1 \mathrm{H}, \mathrm{br},-\mathrm{OH}) ; 2.21(1 \mathrm{H}, \mathrm{br}$, $J=2.2, \mathrm{H}-9 \mathrm{~b}) ; 2.13(1 \mathrm{H}, m, \mathrm{H}-5 \alpha) ; 1.92(1 \mathrm{H}, m, \mathrm{H}-5 \beta) ; 1.80(1 \mathrm{H}, d d d, J=2.7,4.7$ and $13.2 \mathrm{~Hz}$, $\mathrm{H}-9 \beta) ; 1.61$ (1H, $m, \mathrm{H}-8 \beta) ; 1.49$ (2H, $m, \mathrm{H}-8 \alpha$ and $7 \beta) ; 1.31$ (3H, $m, \mathrm{H}-5 \mathrm{a}, 9 \alpha$ and $7 \alpha) ; 0.93 ; 0.90(6 \mathrm{H}$, $2 s, 10-\mathrm{Me}$ and 11); $0.83(3 \mathrm{H}, s, 12-\mathrm{Me}) .{ }^{13} \mathrm{C}-\mathrm{NMR}: \delta 136.5$ (C-3a), 117.1 (C-4), 99.4 (C-1), 68.9 (C-3), 61.6 (C-9b), 49.8 (C-5a), 42.4 (C-7), 39.8 (C-9), 33.4 (C-9a), 33.1 (C-11), 32.9 (C-6), $23.6(\mathrm{C}-5), 21.5(\mathrm{C}-10), 18.5(\mathrm{C}-8), 14.0(\mathrm{C}-12)$. MS $m / z(\mathrm{EI}): 236\left[\mathrm{M}^{+}\right]$. All these data agree with the literature values [14].

3.1.4. Synthesis of (-)-(1R,4aS,8aS)-5,5,8a-Trimethyl-2-vinyl-1,4,4a,5,6,7,8,8a-octahydro naphtalene1-carbaldehyde (8) [11]

Compound 1 (2.14 mmol) was dissolved in anhydrous THF $(5 \mathrm{~mL})$, the solution was stirred at $0{ }^{\circ} \mathrm{C}$ under nitrogen, and Tebbe's reagent $\left[\left(\mathrm{C}_{5} \mathrm{H}_{5}\right)_{2} \mathrm{TiCH}_{2} \mathrm{ClAl}\left(\mathrm{CH}_{3}\right)_{2}\right](4 \mathrm{~mL}$ of a $0.5 \mathrm{M}$ solution in toluene, $2.0 \mathrm{mmol}$ ) was added dropwise. The dark brown solution was allowed to warm to room temperature for $10 \mathrm{~min}, 0.1 \mathrm{M} \mathrm{NaOH}$ solution was added (10 drops) and the slurry was filtered through a short pad of silica gel. The filtrate was evaporated and purified by $\mathrm{CC}$ to give compound $\mathbf{8}$ as a colorless oil, yield 25\%; $[\alpha]_{\mathrm{D}}{ }^{25}-17^{\circ}\left(\mathrm{CHCl}_{3}, c=1.0\right)$; IR (film) $v_{\max } 3090,2720,1719,1643,1607 \mathrm{~cm}^{-1} .{ }^{1} \mathrm{H}-\mathrm{NMR}$ : $\delta 9.48(1 \mathrm{H}, d, J=5.1 \mathrm{~Hz}, \mathrm{C} \underline{\mathrm{HO}}) ; 6.35(1 \mathrm{H}, d d, J=11.2$ and $17.9 \mathrm{~Hz}, \mathrm{Hc}) ; 6.14-6.11(1 \mathrm{H}, m, \mathrm{H}-3)$; $4.93(1 \mathrm{H}, d, J=11.2 \mathrm{~Hz}, \mathrm{Ha}) ; 4.82(1 \mathrm{H}, d, J=17.9 \mathrm{~Hz}, \mathrm{Hb}) ; 2.82(1 \mathrm{H}, \mathrm{brs}, \mathrm{H}-1) ; 2.29-2.19$ (2H, $m$, $\mathrm{H}-4 \alpha$ and $\beta)$; $1.87-1.81$ (1H, $m, \mathrm{H}-8 \beta) ; 1.54-1.15(6 \mathrm{H}, m, \mathrm{H}-8 \alpha, \mathrm{H}-7 \alpha$ and $\beta, \mathrm{H}-6 \alpha$ and $\beta, \mathrm{H}-4 \mathrm{a}) ; 1.03$ $(3 \mathrm{H}, s, 8 \mathrm{a}-\mathrm{Me}) ; 0.95$ and $0.91(6 \mathrm{H}, 2 s, 5-\mathrm{Me} \alpha$ and $\beta) .{ }^{13} \mathrm{C}-\mathrm{NMR}: \delta 206.7(\underline{\mathrm{CHO}}) ; 138.5(=\underline{\mathrm{CH}})$; 132.8 (C-3); 131.5 (C-2); $112.4\left(=\underline{\mathrm{CH}}_{2}\right) ; 62.6$ (C-1); 48.9 (C-4a); 41.9 (C-6); 40.2 (C-8); 37.3 (C-8a); 33.3 (5-Me); 33.1 (C-5); 24.1 (C-4); 22.3 (5-Me); 18.1 (C-7); 15.5 (8a-Me). MS m/z (EI): 232 [M ${ }^{+}$. All these data are coincident with the literature [13].

\subsubsection{Synthesis of $(+)-(5 S, 10 S)-(9 S)-7-D r i m e n e-11,12$ diol (isodrimendiol, 9)}

To a magnetically well-stirred solution of $2(1.06 \mathrm{mmol})$ in $\mathrm{MeOH}(20 \mathrm{~mL})$ acidified with 5 drops of $1 \mathrm{M} \mathrm{HCl}, \mathrm{NaBH}_{4}(4.2 \mathrm{mmol})$ was added carefully in small portions. The mixture was refluxed at $50{ }^{\circ} \mathrm{C}$ for $4 \mathrm{~h}$ and most of the solvent was evaporated in vacuo. Water $(20 \mathrm{~mL})$ was added cautiously and extractions with EtOAc were performed. The organic phase was dried with $\mathrm{MgSO}_{4}$, evaporated and submitted to $\mathrm{CC}$ to give compound $9(0.83 \mathrm{mmol})$ as white solid, yield $78 \%, \mathrm{mp}: 129{ }^{\circ} \mathrm{C}$; $[\alpha]_{\mathrm{D}}{ }^{25}$ $+10^{\circ}\left(\mathrm{CHCl}_{3}, c=1.0\right)$. IR (film) $v_{\max } 3286,2924,1640,1045 \mathrm{~cm}^{-1} .{ }^{1} \mathrm{H}-\mathrm{NMR}: \delta 5.83(1 \mathrm{H}, t, J=3.5 \mathrm{~Hz}$, $\mathrm{H}-7) ; 4.13(1 \mathrm{H}, d, J=12.0 \mathrm{~Hz}, \mathrm{H}-12 \mathrm{~B}) ; 4.00(1 \mathrm{H}, d, J=12.0 \mathrm{~Hz}, \mathrm{H}-12 \mathrm{~A}) ; 3.92(1 \mathrm{H}, d d, J=4.5$ and $11.0 \mathrm{~Hz}, \mathrm{H}-11 \mathrm{~B}) ; 3.64(1 \mathrm{H}, d d, J=5.4$ and $11.0 \mathrm{~Hz}, \mathrm{H}-11 \mathrm{~A}) ; 2.60(2 \mathrm{H}, \mathrm{brs}, 2 \mathrm{OH}) ; 2.20-1.90(3 \mathrm{H}, m$, $\mathrm{H}-6 \alpha$ and $\beta, \mathrm{H}-9 \beta) ; 1.67-1.20$ (7H, $m, \mathrm{H}-1 \alpha$ and $\beta, \mathrm{H}-2 \alpha$ and $\beta, \mathrm{H}-3 \alpha$ and $\beta, \mathrm{H}-5) ; 0.92$ (6H, 2s, 15-Me and 14-Me); 0.88 (3H, s, 13-Me). ${ }^{13} \mathrm{C}-\mathrm{NMR}: \delta 137.2$ (C-8); 127.5 (C-7); 67.7 (C-12); 63.1 (C-11); 54.1 (C-5); 43.4 (C-9); 42.7 (C-3); 36.5 (C-1); 35.9 (C-10); 33.1 (C-4); 33.0 (C-15); 24.3 (C-6); 22.0 (C-14); 21.7 (C-13); $18.8(\mathrm{C}-2)$. MS $m / z(E I): 238\left[\mathrm{M}^{+}\right]$. All these data are in agreement with the literature values [16]. 
3.1.6. Synthesis of $(+)[(1 R, 4 \mathrm{a} S, 8 \mathrm{a} S)-2,5,5,8 \mathrm{a}-$ Tetramethyl-1,4,4a,5,6,7,8,8a-octahydro naphthalen-1yl]methanol (isodrimenol, 10)

Diol 9 (0.34 mmol) was dissolved in DCM $(15 \mathrm{~mL})$ and catalytic quantities of $\mathrm{Pd} / \mathrm{C}(10 \% \mathrm{Pd})$ were added. The mixture was left under a hydrogen atmosphere during $4 \mathrm{~h}$ and the reaction product was filtered, concentrated and purified by CC. Compound $10(0.29 \mathrm{mmol})$ was thus obtained in $85 \%$ yield; $[\alpha]_{\mathrm{D}}{ }^{25}+10^{\circ}\left(\mathrm{CHCl}_{3}, c=1.0\right)$; IR (film) $v_{\max } 3405,2922,1620 \mathrm{~cm}^{-1} ;{ }^{1} \mathrm{H}-\mathrm{NMR}: \delta 5.57(1 \mathrm{H}, m, \mathrm{H}-7)$; $3.74(2 \mathrm{H}, \mathrm{br} d, J=3.0, \mathrm{H}-11 \mathrm{~A}$ and $\mathrm{B}) ; 1.74$ (3H, brs, 12-Me); $2.10-1.20(10 \mathrm{H}, m, \mathrm{H}-1 \alpha$ and $\beta, \mathrm{H}-2 \alpha$ and $\beta, \mathrm{H}-3 \alpha$ and $\beta, \mathrm{H}-5, \mathrm{H}-6 \alpha$ and $\beta, \mathrm{H}-9) ; 0.93$ (3H, s, 15-Me); 0.91 and 0.87 (6H, 2s, 13-Me and 14-Me). ${ }^{13} \mathrm{C}-\mathrm{NMR}: \delta 131.1$ (C-8); 124.6 (C-7); 61.3 (C-11); 57.6 (C-5); 43.4 (C-9); 42.7 (C-3); 36.8 (C-1); 36.1 (C-10); 33.2 (C-13); 33.0 (C-4); 24.0 (C-6); 23.0 (C-14); 22.2 (C-12); 21.7 (C-2); $18.8(\mathrm{C}-15) . \mathrm{MS} m / z(\mathrm{EI}): 222\left[\mathrm{M}^{+}\right]$. All these data are in agreement with the literature $[14,17]$.

\subsubsection{Synthesis of (-)-7 $\alpha, 8$-Epoxy-(9S)-drimane-11,12-diol (11) [20]}

To a solution of diol 9 (4.2 mmols) in $\mathrm{CH}_{2} \mathrm{Cl}_{2}(30 \mathrm{~mL})$ MCPBA acid $(5.4 \mathrm{mmol})$ was added in small portions at $\mathrm{rt}$ during $10 \mathrm{~min}$. Stirring was continued at $\mathrm{rt}$ for $35 \mathrm{~min}$. The reaction mixture was washed with $\mathrm{NaHCO}_{3}$ and water, dried and concentrated. The residue was chromatographed over silica gel to afford compound 11 (75\% yield); mp: $105^{\circ} \mathrm{C}$; $[\alpha]_{\mathrm{D}}{ }^{25}-69^{\circ}\left(\mathrm{CHCl}_{3}, c=1.0\right)$; IR (film) $v_{\max } 3280$, 3120, $3050 \mathrm{~cm}^{-1}$. ${ }^{1} \mathrm{H}-\mathrm{NMR}: \delta 3.95-3.45(4 \mathrm{H}, m, \mathrm{H}-11 \mathrm{~A}$ and $\mathrm{B}, \mathrm{H}-12 \mathrm{~A}$ and B); $3.36(1 \mathrm{H}, \mathrm{H}-7)$; $2.1(1 \mathrm{H}, d d, J=4.5$ and $15.3 \mathrm{~Hz}, \mathrm{H}-9) ; 1.74-1.64(2 \mathrm{H}, m, \mathrm{H}-6 \alpha$ and $\beta) ; 1.61-1.10(7 \mathrm{H}, m \mathrm{H}-1 \alpha$ and $\beta$, $\mathrm{H}-2 \alpha$ and $\beta, \mathrm{H}-3 \alpha$ and $\beta, \mathrm{H}-5) ; 0.96(3 \mathrm{H}, s, 15-\mathrm{Me}) ; 0.89$ and $0.86(6 \mathrm{H}, 2 s, 13-\mathrm{Me}$ and 14-Me). ${ }^{13} \mathrm{C}-\mathrm{NMR}$ : $\delta 66.6$ (C-12); 62.0 (C-8); 60.6 (C-11); 56.8 (C-7); 48.3 (C-9); 42.4 (C-3); 39.0 (C-5); 36.2 (C-1); 34.9 (C-10); 32.9 (C-15); 32.8 (C-4); 22.8 (C-6); 22.7 (C-14); 22.2 (C-13); 18.3 (C-2). MS $\mathrm{m} / z(\mathrm{EI}): 254\left[\mathrm{M}^{+}\right]$. All these data are in agreement with the literature [20].

\subsubsection{Synthesis of (-)-(9S)-Drimane-8,11,12-triol (12) [20]}

To a stirred mixture of $\mathrm{LiAlH}_{4}(16 \mathrm{mmol})$ in dry THF $(50 \mathrm{~mL})$, a solution of the epoxide 11 (4.5 mmol) in dry THF $(30 \mathrm{~mL})$ was added and the mixture was heated at reflux temperature under nitrogen for $4 \mathrm{~h}$. The excess of reagent was decomposed by the addition of EtOAc and an aqueous solution of $\mathrm{HCl}(10 \%)$. The mixture was extracted with EtOAc and the organic phase was washed with $\mathrm{NaHCO}_{3}$ and water, dried and concentrated to give compound $12(85 \%$ yield $)$; mp: $118^{\circ} \mathrm{C} ;[\alpha]_{\mathrm{D}}{ }^{25}-41^{\circ}$ $\left(\mathrm{CHCl}_{3}, c=1.0\right)$; IR (film) $v_{\max } 3400,3280,3120 \mathrm{~cm}^{-1} .{ }^{1} \mathrm{H}-\mathrm{NMR}: \delta 4.0(2 \mathrm{H}, \mathrm{m}, \mathrm{H}-12 \mathrm{~A}$ and B); 3.83-3.60 (3H, $m, \mathrm{H}-11 \mathrm{~A}$ and $\mathrm{B}$ and $1 \mathrm{OH}) ; 3.33(1 \mathrm{H}, \mathrm{brs}, 1 \mathrm{OH}) ; 2.58(1 \mathrm{H}, \mathrm{brs}, 1 \mathrm{O} \underline{\mathrm{H}}) ; 1.89(1 \mathrm{H}, m$, $\mathrm{H}-9)$; $1.80-1.10(11 \mathrm{H}, m, \mathrm{H}-1 \alpha$ and $\beta, \mathrm{H}-2 \alpha$ and $\beta, \mathrm{H}-3 \alpha$ and $\beta, \mathrm{H}-5, \mathrm{H}-6 \alpha$ and $\beta, \mathrm{H}-7 \alpha$ and $\beta$ ); 1.05 (3H, $s, 15-\mathrm{Me}) ; 0.87$ and 0.80 (6H, 2s, 13-Me and 14-Me). ${ }^{13} \mathrm{C}-\mathrm{NMR}: \delta 76.4$ (C-8); 69.5 (C-12); 60.9 (C-11); 56.9 (C-5); 48.6 (C-9); 42.1 (C-3); 37.6 (C-10); 37.4 (C-1); 33.4 (C-4); 33.1 (C-7); 33.0 (C-15); 23.7 (C-14); 21.8 (C-13); 20.0 (C-6); 18.8 (C-2). MS $m / z$ (EI): $256\left[\mathrm{M}^{+}\right]$. All these data are in agreement with the literature [20]. 


\subsubsection{Synthesis of (-)-11-Hydroxy-(9R)-12-nordriman-8-one (13) [20]}

To a stirred solution of $\mathrm{NaIO}_{4}(3.53 \mathrm{mmol})$ in water $(15 \mathrm{~mL})$, a solution of the triol $12(2.54 \mathrm{mmol})$ in $\mathrm{MeOH}(10 \mathrm{~mL})$ was added at $\mathrm{rt}$ during $1.5 \mathrm{~h}$. The reaction solution was extracted with EtOAc and the organic phase was washed with $\mathrm{NaHCO}_{3}$ and water, dried and concentrated to give compound $\mathbf{1 3}$ (90\% yield); mp: $112{ }^{\circ} \mathrm{C}$; $[\alpha]_{\mathrm{D}}{ }^{25}-22^{\circ}\left(\mathrm{CHCl}_{3}, c=1.0\right)$; IR (film) $v_{\max } 3280,1720 \mathrm{~cm}^{-1} .{ }^{1} \mathrm{H}-\mathrm{NMR}: \delta$ $3.98(1 \mathrm{H}, \mathrm{br} d, J=10 \mathrm{~Hz}, \mathrm{H}-11 \mathrm{~A}) ; 3.91(1 \mathrm{H}, \mathrm{br} d, J=10 \mathrm{~Hz}, \mathrm{H}-11 \mathrm{~B}) ; 2.36-2.09$ (2H, $m, 2 \mathrm{H}-7) ; 2.37$ $(1 \mathrm{H}, d d, J=4.3$ and $1.8 \mathrm{~Hz}, \mathrm{H}-9 \beta) ; 2.11(1 \mathrm{H}, d d d, J=1.6,6.2$ and $9.8 \mathrm{~Hz}, \mathrm{H}-7) ; 1.95(1 \mathrm{H}, m, \mathrm{H}-7)$; $1.70-1.16(9 \mathrm{H}, m, \mathrm{H}-1 \alpha$ and $\beta, \mathrm{H}-2 \alpha$ and $\beta, \mathrm{H}-3 \alpha$ and $\beta, \mathrm{H}-5, \mathrm{H}-6 \alpha$ and $\beta$ ); 0.94 (3H, $s, 15-\mathrm{Me}) ; 0.92$ and $0.84\left(6 \mathrm{H}, 2 s, 13-\mathrm{Me}\right.$ and 14-Me). ${ }^{13} \mathrm{C}-\mathrm{NMR}$ : $\delta 214.8$ (C-8); 67.0 (C-9); 60.1 (C-11); 46.0 (C-5); 42.2 (C-3); 40.0 (C-10); 39.3 (C-1); 36.8 (C-7); 33.5 (C-15); 33.4 (C-4); 23.2 (C-6); 22.2 (C-13); 22.0 (C-14); 18.5 (C-2). All these data agree with the literature values [20].

\subsubsection{General Procedure for Synthesis of $\mathbf{1 4}$ and $\mathbf{1 5}[13,16]$}

A magnetically stirred and cold $\left(0^{\circ} \mathrm{C}\right)$ solution of the alcohol substrate $3(10 \mathrm{mmol})$ in acetone $(50 \mathrm{~mL})$ was titrated with Jones reagent, until the orange-brown color of the reagent persisted for 30 seconds. The reaction mixture was stirred for an additional $1 \mathrm{~h}$ at $\mathrm{rt}$, and then isopropanol $(1 \mathrm{~mL})$ was added dropwise to destroy any excess of reagent. Water $(100 \mathrm{~mL})$ was added, and the suspension was extracted with AcOEt, dried with $\mathrm{MgSO}_{4}$, concentrated, and purified by column chromatography to give compounds $14(0.68 \mathrm{mmol})$ and $15(0.85 \mathrm{mmol})$ with yields of 30 and $38 \%$, respectively.

(-)-(1S,8aS)-2,5,5,8a-Tetramethyl-1,4,4a,5,6,7,8,8a-octahydronaphthalene-1-carbaldehyde (drimenal, 14): colorless oil, $[\alpha]_{\mathrm{D}}^{25}-20^{\circ}\left(\mathrm{CHCl}_{3}, c=1.0\right)$; IR (film) $v_{\max } 2923,2851,1714 \mathrm{~cm}^{-1}$. ${ }^{1} \mathrm{H}-\mathrm{NMR}: \delta 9.69(1 \mathrm{H}, d, J=5.1 \mathrm{~Hz}, \mathrm{H}-11) ; 5.70$ (1H, brs, H-7); 2.59 (1H, $\left.m, \mathrm{H}-9\right) ; 2.05$ (2H, $m, \mathrm{H}-6 \alpha$ and $\beta$ ); $1.70-1.10$ (7H, $m, \mathrm{H}-1 \alpha$ and $\beta, \mathrm{H}-2 \alpha$ and $\beta, \mathrm{H}-3 \alpha$ and $\beta, \mathrm{H}-5) ; 1.62$ (3H, $s, 12-\mathrm{Me}) ; 1.05$ (3H, $s$, 15-Me); 0.90 and 0.85 (6H, 2s, 13-Me and 14-Me). ${ }^{13} \mathrm{C}-\mathrm{NMR}: \delta 206.7$ (C-11); 127.8 (C-8); 125.5 (C-7); 67.6 (C-9); 49.1 (C-5); 42.0 (C-3); 40.4 (C-1); 37.0 (C-10); 33.3 (C-14); 33.0 (C-4); 23.7 (C-6); 22.1 (C-13); $21.6(\mathrm{C}-12) ; 18.3(\mathrm{C}-2) ; 15.7(\mathrm{C}-15)$. MS m/z (EI): $220\left[\mathrm{M}^{+}\right]$. All these data are in agreement with the literature [16,21].

(-)-(4aS,8aS)-2,5,5,8a-Tetramethyl-4a,5,6,7,8,8a-hexahydro-4H-naphtalen-1-one (15): white solid; mp: $81^{\circ} \mathrm{C} ;[\alpha]_{\mathrm{D}}{ }^{25}-74^{\circ}\left(\mathrm{CHCl}_{3}, c=1.0\right)$; IR (film) $v_{\max } 2923,1663 \mathrm{~cm}^{-1} .{ }^{1} \mathrm{H}-\mathrm{NMR}: \delta 6.69-6.67(1 \mathrm{H}$, $m, \mathrm{H}-3) ; 2.30-2.25(2 \mathrm{H}, m, \mathrm{H}-4 \alpha$ and $\beta) ; 1.89(1 \mathrm{H}, \mathrm{br} d, J=13.4 \mathrm{~Hz}, \mathrm{H}-8 \beta) ; 1.75(3 \mathrm{H}, d, J=2.0 \mathrm{~Hz}$, Me-2); 1.70-1.10 (6H, $m, \mathrm{H}-8 \alpha, \mathrm{H}-7 \alpha$ and $\beta, \mathrm{H}-6 \alpha$ and $\beta, \mathrm{H}-4 \mathrm{a}) ; 1.04$ (3H, $s, \mathrm{Me}-8 \mathrm{a}) ; 0.99$ and 0.91 (6H, $2 s, \mathrm{Me}-5 \alpha$ and $\beta) .{ }^{13} \mathrm{C}-\mathrm{NMR}: \delta 205.9$ (C-1); 143.4 (C-3); 132.9 (C-2); 49.4 (C-4a); 45.1 (C-8a); 41.6 (C-6); 33.6 (C-5); 33.2 (C-8); 32.3 (Me-5); 24.4 (C-4); 22.3 (Me-5); 18.2 (C-7); 17.1 (Me-8a); $16.4(\mathrm{Me}-2)$. MS $m / z(\mathrm{EI}): 206\left[\mathrm{M}^{+}\right]$. All these data are in agreement with the literature $[13,16,22]$.

3.1.11. Synthesis of (-)-(4aS,8aS)-3,4a,8,8-Tetramethyl-4a,5,6,7,8,8a-hexahydro-1H-naphtalen-2-one (16) $[14,17]$

To a magnetically stirred solution of the alcohol substrate $3(10 \mathrm{mmol})$ in DCM $(50 \mathrm{~mL})$, pyridinium chlorochromate $(10 \mathrm{mmol})$ was added. The brown suspension was stirred overnight, until 
thin layer chromatography analysis showed the disappearance of the starting material. Celite (500 $\mathrm{mg}$ ) and EtOAc $(50 \mathrm{~mL})$ were added to the reaction mixture, and the slurry was filtered through a short pad of silica gel, washing copiously with EtOAc. The filtrate was dried, evaporated, and purified by column chromatography to give compound $16(1.2 \mathrm{mmol})$ with $60 \%$ yield as a colorless oil; $[\alpha]_{\mathrm{D}}{ }^{25}-7^{\circ}$ $\left(\mathrm{CHCl}_{3}, c=1.0\right)$; IR (film) $v_{\max } 2956,1704,1673 \mathrm{~cm}^{-1} .{ }^{1} \mathrm{H}-\mathrm{NMR}: \delta 6,39(1 \mathrm{H}, d, J=1.3 \mathrm{~Hz}, \mathrm{H}-4)$; $2.49(1 \mathrm{H}, d d, J=3.9$ and $17.4 \mathrm{~Hz}, \mathrm{H}-1 \alpha) ; 2.34(1 \mathrm{H}, d d, J=14.0$ and $17.4 \mathrm{~Hz}, \mathrm{H}-1 \beta) ; 1.72(3 \mathrm{H}, d$, $J=1.3 \mathrm{~Hz}, \mathrm{Me}-3) ; 1.72(1 \mathrm{H}, \mathrm{br} d d, J=13.9$ and $3.9 \mathrm{~Hz}, \mathrm{H}-5 \beta) ; 1.70-1.10(6 \mathrm{H}, m, \mathrm{H}-5 \alpha, \mathrm{H}-6 \alpha$ and $\beta$, $\mathrm{H}-7 \alpha$ and $\beta, \mathrm{H}-8 \mathrm{a}) ; 1.07$ (3H, s, Me-4a); $0.91(3 \mathrm{H}, s, \mathrm{Me}-8) ; 0.88(3 \mathrm{H}, s, \mathrm{Me}-8) .{ }^{13} \mathrm{C}-\mathrm{NMR}: \delta 201.6$ (C-2); 158.3 (C-4); 131.2 (C-3); 50.6 (C-8a); 41.2 (C-7); 38.4 (C-5); 36.9 (C-4a); 35.4 (C-1); 32.8 (C-8); 32.2 (Me-8); 20.9 (Me-8); 18.6 (C-6); 18.5 (Me-4a); 15.5 (Me-3). MS m/z (EI): 206 [M ]. All these data are in agreement with the literature $[13,16,22]$.

\subsubsection{Synthesis of $(+)[(1 S, 2 S, 8 \mathrm{a} S)-2,5,5,8 \mathrm{a}-$ Tetramethyldecahydronaphthalen-1-yl]methanol} (drimanol, 17)

Drimenol (3, $0.36 \mathrm{mmol})$ was dissolved in DCM $(10 \mathrm{~mL})$ and catalytic quantities of $\mathrm{Pd} / \mathrm{C}(10 \% \mathrm{Pd})$ were added. The mixture was left under a hydrogen atmosphere during $4 \mathrm{~h}$ and the reaction product was filtered, concentrated and purified by $\mathrm{CC}$ to obtain compound $17(75 \%$ yield $) ;[\alpha]_{\mathrm{D}}{ }^{25}+15^{\circ}\left(\mathrm{CHCl}_{3}\right.$, $c=1.0)$; IR (film) $v_{\max } 3620,2950,1380 \mathrm{~cm}^{-1} .{ }^{1} \mathrm{H}-\mathrm{NMR}: \delta 3.86(1 \mathrm{H}, d d, J=4.5$ and $10.7 \mathrm{~Hz}$, $\mathrm{H}-11 \mathrm{~B}) ; 3.61(1 \mathrm{H}, d d, J=4.5$ and $10.7 \mathrm{~Hz}, \mathrm{H}-11 \mathrm{~A}) ; 2.17(1 \mathrm{H}, m, \mathrm{H}-8) ; 1.65-1.10(12 \mathrm{H}, m, \mathrm{H}-1 \alpha$ and $\beta, \mathrm{H}-2 \alpha$ and $\beta, \mathrm{H}-3 \alpha$ and $\beta, \mathrm{H}-5, \mathrm{H}-6 \alpha$ and $\beta, \mathrm{H}-7 \alpha$ and $\beta, \mathrm{H}-9) ; 0.98(3 \mathrm{H}, d, J=7.5 \mathrm{~Hz}, 12-\mathrm{Me}) ; 0.88$ and $0.83\left(9 \mathrm{H}, 3 s, 13-\mathrm{Me}\right.$ and 15-Me). ${ }^{13} \mathrm{C}-\mathrm{NMR}: \delta 61.0$ (C-11); 56.5 (C-5); 55.7 (C-9); 41.9 (C-3); 39.9 (C-1); 37.6 (C-10); 34.5 (C-7); 33.6 (C-14); 33.2 (C-4); 28.5 (C-8); 21.6 (C-13); 18.4 (C-6); $17.5(\mathrm{C}-2) ; 17.1(\mathrm{C}-15), 15.6(\mathrm{C}-12)$. MS $m / z(\mathrm{EI}): 224\left[\mathrm{M}^{+}\right]$. All these data are in agreement with the literature [23].

\subsection{Antifungal Evaluation}

\subsubsection{Microorganisms and Media}

For the antifungal evaluation, standardized strains from the American Type Culture Collection (ATCC), Rockville, MD, USA, and CEREMIC (CCC), Centro de Referencia en Micología, Facultad de Ciencias Bioquímicas y Farmacéuticas, Suipacha 531 (2000)-Rosario, Argentina, were used in a first instance screening: C. albicans ATCC 10231, S. cerevisiae ATCC 9763, C. neoformans ATCC 32264, A. flavus ATCC 9170, A. fumigatus ATTC 26934, A. niger ATCC 9029, T. rubrum CCC 110, T. mentagrophytes ATCC 9972, and M. gypseum CCC 115.

Strains were grown on Sabouraud-chloramphenicol agar slants for $48 \mathrm{~h}$ at $30{ }^{\circ} \mathrm{C}$, maintained on slopes of Sabouraud-dextrose agar (SDA, Oxoid), and sub-cultured every 15 days to prevent pleomorphic transformations. Inocula of cells or spore suspensions were obtained according to reported procedures and adjusted to $1-5 \times 10^{3}$ cells/spores with colony forming units $(\mathrm{CFU}) / \mathrm{mL}[11,12]$. 


\subsubsection{Antifungal Susceptibility Testing}

Minimum inhibitory concentration (MIC) of each compound was determined by using broth microdilution techniques according to the guidelines of the CLSI for yeasts (M27-A3) and for filamentous fungi (M 38 A2) [11,12]. MIC values were determined in RPMI-1640 (Sigma, St. Louis, MO, USA) buffered to $\mathrm{pH} 7.0$ with MOPS. Microtiter trays were incubated at $35{ }^{\circ} \mathrm{C}$ for yeasts and hialohyphomycetes and at $28-30{ }^{\circ} \mathrm{C}$ for dermatophytes strains in a moist, dark chamber, and MICs were visually recorded at $48 \mathrm{~h}$ for yeasts, and at a time according to the control fungus growth, for the rest of fungi.

For the assay, stock solutions of pure compounds were two-fold diluted with RPMI from 250 to $0.98 \mu \mathrm{g} / \mathrm{mL}$ (final volume $=100 \mu \mathrm{L}$ ) and a final DMSO concentration $\leq 1 \%$. A volume of $100 \mu \mathrm{L}$ of inoculum suspension was added to each well with the exception of the sterility control where sterile water was added to the well instead. Ketoconazole, terbinafine and amphotericin B were used as positive controls.

Endpoints were defined as the lowest concentration of drug resulting in total inhibition $\left(\mathrm{MIC}_{100}\right)$ of visual growth compared to the growth in the control wells containing no antifungal. $\mathrm{MIC}_{50}$ was defined as the lowest concentration of a compound that inhibited $50 \%$ of the growth control, respectively (culture media with the microorganism but without the addition of any compound), and was determined spectrophotometrically with the aid of a VERSA Max microplate reader (Molecular Devices, Sunnyvale, CA, USA).

The Minimum Fungicidal Concentration (MFC) of each compound against each strain was also determined as follows: After determining the $\mathrm{MIC}_{100}$, an aliquot of $5 \mu \mathrm{L}$ sample was withdrawn from each clear well of the microtiter tray and plated onto a 150-mm RPMI-1640 agar plate buffered with MOPS (Remel, Lenexa, KS, USA.). Inoculated plates were incubated at $30{ }^{\circ} \mathrm{C}$, and MFCs were recorded after $48 \mathrm{~h}$. The MFC was defined as the lowest concentration of each compound that resulted in total inhibition of visible growth.

\subsection{Calculations Methods}

The DFT calculations, full geometry optimization and calculation of the harmonic vibrational frequencies were performed using the GAUSSIAN 03 program [53]. Density Functional Theory (DFT) calculations were employed in order to properly account for the electron correlation effects. The widely employed hybrid method denoted by B3LYP was used, along with the double-zeta split valence basis set 6-311G(d,p). This method includes a mixture of HF and DFT exchange terms and the gradient corrected correlation functional of Lee, Yang and Parr [54,55], as proposed and parameterized by Becke [56,57].

A preliminary conformational search was carried out using the GASCOS algorithm [58-60] combined with PM6 an RHF/3-21G calculations. All the conformations obtained using this calculations were confirmed from B3LYP/6311G(d,p) computations. With any conformational search, it is very important to examine the structures obtained to make sure that they are true minima and not transition structures or other structures with very low or zero forces on the atoms (stationary points). Thus, minima were characterized through harmonic frequency analysis employing B3LYP/6311G(d,p) calculations. 
The electronic studies were carried out using molecular electrostatic potentials (MEPs) [61]. The low-energy conformations were obtained from our conformational search. Subsequently, single point calculations were carried out. Thus, these MEPs were calculated using B3LYP/6-311G++(d,p) wave functions and MEPs graphical presentations were created using the MOLEKEL program [62].

\section{Conclusions}

Results obtained here were aimed at contributing to clear up the main structural features necessary for the antifungal activity of drimanes (that have been the subject of contradictory statements in the literature) by testing them against a unique panel of fungal strains, with a standardized methodology, in the same laboratory.

Regarding the absolute configuration of C-9, here we found that compounds with an aldehyde in any of the two possible configurations did possess antifungal activity against $C$. albicans and C. neoformans, although the $9 \alpha$-derivative 2 displays 16 and eight times lower activity than the $9 \beta$-one 1. This result is in contrast with Fujita and Kubo [7], but consistent with Anke and Sterner's [8] and Derita et al.'s [2] previous studies, who both found that $\mathbf{2}$ did display antifungal activities but lower than those of compound 1.

Another result demonstrated that aldehydes at C-9 or C-8 or a $\mathrm{CH}_{2} \mathrm{OH}$ at $\mathrm{C}-8$ would not be a requisite for activity. In addition, this work showed that the $\Delta^{7,8}$.double bond in the drimane scheleton should be considered one of the necessary structural features for antifungal activity, either alone as in compounds 3, 5-10 and 14, or as part of a C-8 $\alpha, \beta$-unsaturated aldehyde moiety (constituting a Michael acceptor group) as in compounds $\mathbf{1}$ and 2. The fact that both drimane structural types do display antifungal activity clearly suggested that antifungal drimanes would not act via a Michael addition. This finding differs from Taniguchi's report [10]. However, as explained in the Introduction, the statement of Taniguchi et al. in [10] contradicted their own previous report [7] in which 2 was shown to be devoid of antifungal activity, although it possessed the $\alpha, \beta$-unsaturated C- 8 aldehyde moiety. In addition, results obtained here showed that the electronic characteristics of drimanes play an important role in their antifungal behavior. Thus, we found that the electronic distribution in the vicinity of the $\Delta^{7,8}$ is important for activity and also we found that the most active compound $\mathbf{1}$ possessed a differential big positive zone in the MEP which could contribute to its high antifungal activity. Regarding the influence of the differential hydrophobocity of compounds in the antifungal behavior, results showed that variations in $\log P$ values were not reflected in a concomitant variation of activity.

\section{Acknowledgements}

SZ acknowledges ANPCyT PICT-2010 0608 and UNR BIO 258. RDE acknowledges ANPCyT, PICT 2010-1832. Grants from Universidad Nacional de San Luis (UNSL) partially supported this work. RDE and FG are members of the Consejo Nacional de Investigaciones Científicas y Técnicas (CONICET-Argentina) staff. 


\section{References}

1. Del Vitto, L.; Petenatti, E.; Petenatti, M. Recursos herbolarios de San Luis (Argentina) 2a parte: Plantas exóticas cultivadas, adventicias y/o naturalizadas. Multequina 1998, 7, 29-48.

2. Derita, M.; Leiva, M.; Zacchino, S. Influence of plant part, season of collection and content of the main active constituent, on the antifungal properties of Polygonum acuminatum Kunth. J. Ethnopharmacol. 2009, 124, 377-383.

3. Mc Callion, R.; Cole, A.; Walker, J.; Blunt, J.; Munro, M. Antibiotic substances from New Zealand plants. Planta Med. 1982, 44, 134-138.

4. De Almeida Alves, T.; Ribeiro, F.; Kloos, H.; Zani, C. Polygodial, the fungitoxic component from the Brazilian medicinal plant Polygonum punctatum. Mem. Inst. Oswaldo Cruz. 2001, 96, 831-833.

5. Taniguchi, M.; Adachi, T.; Oi, S.; Kimura, A.; Katsumura, S.; Isoe, S.; Kubo, I. Structure-activity relationship of the Warburgia sesquiterpene dialdehydes. Agric. Biol. Chem. 1984, 48, 73-78.

6. Lee, S.; Lee, J.; Lunde, C.; Kubo, I. In vitro antifungal susceptibilities of Candida albicans and other fungal pathogens to polygodial, a sesquiterpene dialdehyde. Planta Med. 1998, 65, 204-208.

7. Fujita, K.; Kubo, I. Multifunctional action of antifungal polygodial against Saccharomyces cerevisiae: Involvement of pyrrole formation on cell surface in antifungal action. Bioorg. Med. Chem. 2005, 13, 6742-6747.

8. Anke, H.; Sterner, O. Comparison of the antimicrobial and cytotoxic activities of twenty unsaturated sesquiterpene dialdehydes from plants and mushrooms. Planta Med. 1991, 57, 344-347.

9. Derita, M.; Zacchino, S. Validation of the ethnopharmacological use of Polygonum persicaria for its antifungal properties. Nat. Prod. Commun. 2011, 6, 931-933.

10. Taniguchi, M.; Yano, Y.; Tada, E.; Ikenishi, K.; Oi, S.; Haraguchi, H.; Hashimoti, K.; Kubo, I. Mode of action of polygodial, an antifungal sesquiterpene dialdehyde. Agric. Biol. Chem. 1988, $52,1409-1414$.

11. Clinical and Laboratory Standards Institute (CLSI). Reference Method for Broth Dilution Antifungal Susceptibility Testing for Yeasts (M27 A3), 3rd ed.; CLSI: Wayne, PA, USA, 2008; Volume 28, No. 14, pp. 1-25.

12. Clinical and Laboratory Standards Institute (CLSI). Reference Method for Broth Dilution Antifungal Susceptibility Testing for and for Filamentous Fungi (M38 A2), 2nd ed.; CLSI: Wayne, PA, USA, 2008; Volume 28, No. 16, pp. 1-35.

13. Cuellar, M.; Salas, C.; Cortés, M.; Morello, A.; Maya, J.; Preite, M. Synthesis and in vitro trypanocide activity of several drimane-quinone derivatives. Bioorg. Med. Chem. 2003, 11, 2489-2497.

14. Cuellar, M.; Moreno, L.; Preite, M. Regioselective oxidative fragmentation of drimanic terpene alcohols: a short, easy and efficient access to natural and synthetic 11-nordrimane terpene derivatives. ARKIVOC 2003, 10, 169-177.

15. Sakio, Y.; Hirano, Y.; Hayashi, M.; Komiyama, K.; Ishibashi, M. Dendocarbins A-N, new drimane sesquiterpenes from the nudibranch Dendrodoris carbunculosa. J. Nat. Prod. 2001, 64, 726-731. 
16. Matsuda, H.; Pongpiriyadacha, Y.; Morikawa, T.; Kashima, Y.; Nakano, K.; Yoshikawa, M. Protective effects of polygodial and related compounds on ethanol-induced gastric mucosal lesions in rats: Structural requirements and mode of action. Bioorg. Med. Chem. Lett. 2002, 12, 477-482.

17. Cuellar Fritis, M. Synthesis of sesquiterpenquinones and aza-anthraquinones derivatives using polygodial as chiral synthon. Doctoral Thesis, Pontificia Universidad Católica de Chile, Santiago, Chile, 2002; p. 155.

18. Feng, J.; Yang, C.; Zhang, D.; Wang, J.; Fu, H.; Chen, H.; Li, X. Catalytic transfer hydrogenolysis of $\alpha$-methylbenzyl alcohol using palladium catalysts and formic acid. Appl. Catal. A Gen. 2009, $354,38-43$.

19. Donelly, D.; O'Reilly, J.; Chiaroni, A.; Polonsky, J. Crystal structure and absolute configuration

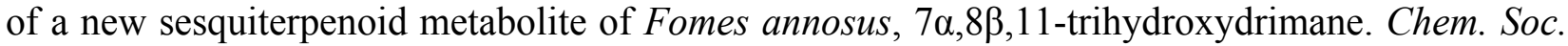
Perkin Trans. 1 1980, 2196-2199.

20. González Sierra, M.; Colombo, M.; Zudenigo, M.; Rúveda, E. ${ }^{13} \mathrm{C}$ NMR spectral analysis of grindelane diterpenoid acids. Phytochemistry 1984, 23, 1685-1689.

21. Cortés, M.; Moreno, L.; López, J. Partial Synthesis of (-)-11,12-dinordriman-8-one and the (-)enantiomer of polywood. J. Chem. Res. (S) 1998, 36-37.

22. Scher, J.; Speakman, J.; Zapp, J.; Becker, H. Bioactivity guided isolation of antifungal compounds from the liverwort Bazzania trilobata (L.) S. F. Gray. Phytochemistry 2004, 65, 2583-2588.

23. Moreno-Osorio, L.; Espinoza, L.; Cuellar, M.; Preite, M. LTA-mediated synthesis and complete assignment of ${ }^{1} \mathrm{H}$ and ${ }^{13} \mathrm{C}$ NMR data of two natural 11-nordrimanes: Isonordrimenone and polygonone. Magn. Reson. Chem. 2007, 45, 993-996.

24. Hellou, J.; Andersen, R. Terpenoids from the dorid nudibranch Cadlina luteomarginata. Tetrahedron 1982, 38, 1875-1879.

25. Zhang, L.; Yan, K.; Zhang, Y.; Huang, R.; Bian, J.; Zheng, Ch.; Sun, H.; Chen, Z.; Sun, N.; An, R.; et al. High-throughput synergy screening identifies microbial metabolites as combination agents for the treatment of fungal infections. Proc. Natl. Acad. Sci. USA 2007, 104, 4606-4011.

26. Singh, N. Impact of current transplantation practices on the changing epidemiology of infections in transplant recipients. Lancet Infect. Dis. 2003, 3, 156-161.

27. Pfaller, M.; Diekema, D. Epidemiology of invasive candidiasis: A persistent public health problem. Clin. Microbiol. Rev. 2007, 20, 133-163.

28. Barrero, A.; Oltra, J.E.; Alvarez, M.; Raslan, D.; Saúde, D.; Akssira, M. New sources and antifungal activity of sesquiterpene lactones. Fitoterapia 2000, 71, 60-64.

29. Justicia, J.; Álvarez de Cienfuegos, L.; Estévez, R.; Paradas, M.; Lasanta, A.; Oller, J.; Rosales, A.; Cuerva, J.; Oltra, E. Ti-catalyzed transannular cyclization of epoxygermacrolides. Synthesis of antifungal (+)-tuberiferine and (+)-dehydrobrachylaenolide. Tetrahedron 2008, 64, 11938-11943.

30. Vargas L.; Castelli, M.V.; Kouznetsov, V.; Urbina J.; López, S. Sortino, M.; Enriz, R.; Ribas, J.C.; Zacchino, S. In vitro antifungal activity of new series of homoallylamines and related compounds with inhibitory properties of the synthesis of fungal cell wall polymers. Bioorg. Med. Chem. 2003, 11, 1531-1550.

31. Musiol, R.; Jampilek, J.; Buchta, V.; Silva, L.; Niedbala, H.; Podeszwa, B.; Palka, A.; Majerz-Maniecka, K.; Oleksyn, B.; Polanski, J. Antifungal properties of new series of quinoline derivatives. Bioorg. Med. Chem. 2006, 14, 3592-3598. 
32. Setiadi, D.; Chass, G.; Torday, L.; Varro, A.; Papp, J. Vitamin E models. Conformational analysis and stereochemistry of tetralin, chroman, thiochroman and selenochroman. J. Mol. Struct. (Theochem.) 2002, 594, 161-172.

33. Suvire, F.; Andreu, I.; Bermejo, A.; Zamora, M.; Cortés, D.; Enriz, R. Conformational study of N-alkyl-benzyltetrahydroisoquinolines alkaloid. J. Mol. Struct. (Theochem.) 2003, 666, 109-116.

34. Villagra, S.; Bernini, M.; Rodriguez, A.; Zacchino, S.; Kouznetsov, V.; Enriz, R. Conformational and electronic study of homoallylamines with inhibitory properties against polymers of fungal cell wall. J. Mol. Struct. (Theochem.) 2003, 666, 587-598.

35. Politzer, P.; Truhlar, D. Chemical Applications of Atomic and Molecular Electrostatic Potentials; Plenum Publishing: New York, NY, USA, 1981.

36. Carrupt, P.; El Tayar, N.; Karlén, A.; Festa, B. Molecular electrostatic potentials for characterizing drug-biosystem interactions. Methods Enzymol. 1991, 202, 638-650.

37. Greeling, P.; Langenaeker, W.; De Proft, F.; Baeten, A. Molecular Electrostatic Potentials: Concepts and Applications. Theoretical and Computational Chemistry; Elsevier Science B.V.: Amsterdam, The Netherlands, 1996; p. 587.

38. Voda, K.; Boh, B.; Vrtacnik, M. A quantitative structure-antifungal activity relationship study of oxygenated aromatic essential oil compounds using data structuring and PLS regression analysis J. Mol. Model. 2004, 10, 76-84.

39. Leal, P.; Mascarello, A.; Derita, M.; Zuljan, F.; Nunes, R.; Zacchino, S.; Yunes, R. Relation between lipophylicity of alkyl gallates and antifungal activity against yeasts and filamentous fungi. Bioorg. Med. Chem. Lett. 2009, 19, 1793-1796.

40. Meléndez Gómez, C.; Kouznetsov, V.; Sortino, M.; Alvarez, S.; Zacchino, S. In vitro antifungal activity of polyfunctionalized 2-(hetero)arylquinolines prepared through imino Diels Alder reactions. Bioorg. Med. Chem. 2008, 16, 7908-8920.

41. Barfknecht, C.; Nichols, D. Correlation of psychotomimetic activity of phenetylamines and amphetamines with 1-octanol-water partition coefficients. J. Med. Chem. 1975, 18, 208-210.

42. López, S.; Castelli, M.; Zacchino, S.; Domínguez, J.; Lobo, G.; Charris-Charris, J.; Cortés, J.; Ribas, J.; Devia, C.; Rodríguez, A.; Enriz, R. In vitro antifungal evaluation and structure-activity relationships of a new series of chalcone derivatives and synthetic analogues, with inhibitory properties against polymers of the fungal cell wall. Bioorg. Med. Chem. 2001, 9, 1999-2013.

43. Jansen, B.; de Groot, A. Occurrence, biological activity and synthesis of drimane sesquiterpenoids. Nat. Prod. Rep. 2004, 21, 449-477.

44. Appel, H.; Bond, R.; Overton, K. The constitution and stereochemistry of valdiviolide, fuegin, winterin and futronolide. Tetrahedron 1963, 19, 635-641.

45. Ying, B.; Peiser, G.; Ji, Y.; Mathias, K.; Tutko, D.; Hwang, Y. Phytotoxic sesquiterpenoids from Canella winterana. Phytochemistry 1995, 38, 909-915.

46. Barnes, C.; Loder, J. The structure of polygodial: A new sesquiterpene dialdehyde from Polygonum hydropiper L. Austr. J. Chem. 1962, 15, 322-327.

47. Guillerm, D.; Delarue, M.; Jalali-Naini, M.; Lemaître, P.; Lallemand, J-Y. Synthesis of all possible stereoisomers of polygodial. Tetrahedron Lett. 1984, 25, 1043-1048. 
48. Castelli, V.; Lodeyro, A.; Malheiros, A.; Zacchino, S.; Roveri, O. Inhibition of the mitochondrial ATP synthesis by polygodial, a naturally occurring dialdehyde unsaturated sesquiterpene. Biochem. Pharmacol. 2005, 70, 82-89.

49. Malheiros, A.; Cechinel Filho, V.; Schmitt, C.; Yunes, R.; Escalante, A.; Svetaz, L.; Zacchino, S.; Delle Monache, F. Antifungal activity of drimane sesquiterpenes from Drimys brasiliensis using bioassay-guided fractionation. J. Pharm. Pharm. Sci. 2005, 8, 335-339.

50. Rodriguez, B.; Zapata, N.; Medina, P.; Viñuela, E. A complete ${ }^{1} \mathrm{H}$ and ${ }^{13} \mathrm{C}$ NMR data assignment for four drimane sesquiterpenoids isolated from Drimys winterii. Magn. Reson. Chem. 2005, 43, $82-84$.

51. Urban, S.; Capon, R. Absolute stereochemistry of puupehenone and related metabolites. J. Nat. Prod. 1996, 59, 900-901.

52. Hueso-Rodriguez, J.; Rodríguez, B. A new and efficient route to optically active drimanes. Synthesis of $(+)$-winterin, $(+)$-confertifolin, $(+)$-isodrimenin and $(+)$-bicyclofarnesol. Tetrahedron 1989, 45, 1567-1576.

53. Frisch, M.; Trucks, G.; Schlegel, H.; Scuseria, G.; Robb, M.; Cheeseman, J.; Montgomery, J., Jr.; Vreven, T.; Kudin, K.; Burant, J.; et al. Gaussian 03, Revision B.05; Gaussian, Inc.: Pittsburgh, PA, USA, 2003.

54. Lee, C.; Yang, W.; Parr, R. Development of the Colle-Salvetti correlation-energy formula into a functional of the electron density. Phys. Rev. B 1988, 37, 785-789.

55. Miehlich, B.; Savin, A.; Stoll, H.; Preuss, M. Results obtained with the correlation energy density functionals of Becke and Lee, Yang and Parr. Chem. Phys. Lett. 1989, 157, 200-207.

56. Becke, A. Density-functional exchange-energy approximation with correct asymptotic behavior. Phys. Rev. A 1988, 38, 3098-3100.

57. Becke, A. Density-functional thermochemistry. III. The role of exact exchange. J. Chem. Phys. 1993, 98, 5648-5652.

58. Santagata, L.; Suvire, F.; Enriz, R.; Torday, L.; Csizmadia, I. A geometrical algorithm to search the conformational space of flexible molecules. J. Mol. Struct. (Theochem.) 1999, 465, 33-67.

59. Santagata, L.; Suvire, F.; Enriz, R. An analytic ring closure condition for geometrical algorithm to search the conformational space. J. Mol. Struct. (Theochem.) 2000, 507, 89-95.

60. Santagata, L.; Suvire, F.; Enriz, R. Partially relaxed ring closure conditions for geometrical algorithm to search the conformational space for minimum energy conformations. J. Mol. Struct. (Theochem.) 2001, 536, 173-188.

61. Politzer, P.; Daiker, K. The Force Concept in Chemistry; Deb, M.B., Ed.; van Nostrand Reinhold: New York, NY, USA, 1981.

62. Flükiger, P.; Lüthi, H.; Portmann, S.; Weber, J. MOLEKEL 4.0; Swiss Center for Scientific Computing: Manno, Switzerland, 2000.

Sample Availability: Samples of the compounds 1-4 are available from the authors.

(C) 2013 by the authors; licensee MDPI, Basel, Switzerland. This article is an open access article distributed under the terms and conditions of the Creative Commons Attribution license (http://creativecommons.org/licenses/by/3.0/). 